\title{
Origin and Molecular Specification of Striatal Interneurons
}

\author{
Oscar Marín, Stewart A. Anderson, and John L. R. Rubenstein \\ Department of Psychiatry, Nina Ireland Laboratory of Developmental Neurobiology, Langley Porter Psychiatric Institute, \\ University of California, San Francisco, San Francisco, California 94143-0984
}

\begin{abstract}
The striatum, the largest component of the basal ganglia, contains projection neurons and interneurons. Whereas there is considerable agreement that the lateral ganglionic eminence (LGE) is the origin of striatal projection neurons, less is known about the origin of striatal interneurons. Using focal injections of retrovirus into the ventral telencephalon in vitro, we demonstrate that most striatal interneurons tangentially migrate from the medial ganglionic eminence (MGE) or the adjacent preoptic/anterior entopeduncular areas (POa/AEP) and express the NKX2.1 homeodomain protein. Although the majority of striatal interneurons (cholinergic, calretinin ${ }^{+}$, and parvalbumin ${ }^{+}$) maintain the expression of NKX2.1 into adulthood, most of the interneurons expressing somatostatin (SOM), neuropeptide Y (NPY), and neural nitric oxide synthase (NOS) appear to downregulate the expression of NKX2.1 as they exit the neuroepithelium. Analysis of striatal development in mice lacking $N k \times 2.1$ suggests that this gene is
\end{abstract}

The integration of complex information within a neural system frequently requires the coordinated activity of projection neurons and interneurons. In the striatum, the largest component of the basal ganglia, projection neurons comprise $90 \%$ of the cells, give rise to its outputs, and receive nearly all of the synapses from extrinsic striatal afferents as well as from the striatal interneurons (for review, see Heimer, 1995; Parent and Hazrati, 1995; Gerfen and Wilson, 1996). Interneurons, on the other hand, comprise only $\sim 10 \%$ of striatal cells and are implicated in regulating striatal projection function (for review, see Kawaguchi et al., 1995; Kawaguchi, 1997).

The mechanisms that control the generation of different striatal neuronal subtypes and their assembly into functional circuits are poorly understood. The basal ganglia (striatum and pallidum) derive from both the lateral and the medial ganglionic eminences in the telencephalon (LGE and MGE, respectively). Striatal projection neurons are thought to derive from the LGE (Deacon et al., 1994; Olsson et al., 1995, 1998; Anderson et al., 1997a), and Dlx1,2,5,6, Gsh2, Mash1, and retinoid receptor transcription factors have been implicated in the control of their specification and differentiation (Porteus et al., 1994; Hsieh-Li et al., 1995; Anderson et al., 1997a; Szucsik et al., 1997; Casarosa et al., 1999; Eisenstat et al., 1999; Toresson et al., 1999). For instance, the Dlx genes are

\footnotetext{
Received Feb. 28, 2000; revised May 17, 2000; accepted May 19, 2000.

This work was supported by research grants to J.L.R.R. from Nina Ireland, National Alliance for Research on Schizophrenia and Depression, National Institute on Drug Abuse (R01 DA12462), and National Institute of Mental Health (NIMH; R01 MH49428-01, R01 MH51561-01A1, and K02 MH01046-01); and to S.A. from NIMH (K08-MH01620). O.M. is supported by a postdoctoral fellowship from the Spanish Ministerio de Educación y Ciencia. We are very gratef ul to J. E. Johnson for providing the Mash1 mutant mice; to H. Hemmings for the DARPP-32 antibody; to D. H. Lowenstein for the LacZ-expressing pseudotyped retrovirus; to A. Bagri for help with the retrovirus injection and manipulation; to C. Horn for technical help on the preparation of slice cultures; to L. Lu for help with mice genotyping; to V. Pachnis (Lhx6 and $L h x 7)$ and C. Gerfen $(E N K)$ for mouse cDNA; and to members of the Rubenstein's lab for helpful comments and discussions.

Correspondence should be addressed to Dr. John L. R. Rubenstein, Department of Psychiatry, Nina Ireland Laboratory of Developmental Neurobiology, Langley Porter Psychiatric Institute, Box F-0984, University of California, San Francisco, 401 Parnassus Avenue, San Francisco, CA 94143-0984. E-mail: jlrr@cgl.ucsf.edu.

Copyright (C) 2000 Society for Neuroscience $0270-6474 / 00 / 206063-14 \$ 15.00 / 0$
}

required for the specification of nearly all striatal interneurons. Similar analysis of mice lacking the Mash1 basic helix-loop-helix (bHLH) or both the DIx1 and D/x2 homeodomain transcription factors demonstrates that these genes are required for the differentiation of striatal interneurons. Mash1 mutants primarily have a reduction in early-born striatal interneurons, whereas DIx1/2 mutants primarily have reduced numbers of late-born striatal interneurons. We also present evidence implicating the $L h x 6$ and $L h x 7$ LIM-homeobox genes in the development of distinct interneuron subtypes. Finally, we hypothesize that, within the MGE, radially migrating cells generally become projection neurons, whereas tangentially migrating cells mainly form interneurons of the striatum and cerebral cortex.

Key words: NKX2.1; DLX; MASH1; LHX; basal ganglia; interneuron; medial ganglionic eminence; lateral ganglionic eminence; striatum; neuron identity; neuronal specification; telencephalon homeodomain transcription factors that are expressed in overlapping patterns during the differentiation of basal telencephalic neurons (Anderson et al., 1997a; Eisenstat et al., 1999). Mice lacking $D l x 1$ and Dlx2 have a block in the differentiation of late-born neurons in the basal telencephalon, which affects to a large number of projection neurons of the striatum as well as interneurons of the cerebral cortex and olfactory bulb (Anderson et al., 1997a,b; Bulfone et al., 1998). In addition, Mash1 encodes a basic helix-loophelix transcription factor that is required for the development of early-born neurons in the basal telencephalon and some cortical interneurons (Casarosa et al., 1999).

Unlike striatal projection neurons, the origin of striatal interneurons and the genetic control of their development are poorly understood. Striatal interneurons comprise four major classes: (1) cholinergic neurons; (2) GABAergic neurons containing calretinin (CR); (3) GABAergic neurons containing parvalbumin (PV); and (4) GABAergic neurons containing somatostatin (SOM), neuropeptide Y (NPY), and neuronal nitric oxide synthase (NOS) (for review, see Kawaguchi et al., 1995) (but also see FigueredoCardenas et al., 1996). Previous transplantation studies in the rat have suggested that $\mathrm{SOM}^{+}$interneurons mainly derive from the LGE, whereas cholinergic interneurons may derive from the MGE (Olsson et al., 1998). The origin of the GABAergic interneurons containing PV or CR has not been elucidated. Recent studies have found that there are migrations of cells from the MGE into the LGE (Sussel et al., 1999; Wichterle et al., 1999), raising the possibility that some striatal cells are derived from the MGE. Furthermore, the expression pattern of the $N k x 2.1$ homeobox gene suggests that at least some of these migrating cells may express this gene. Although it is known that $N k \times 2.1$ is required for the specification of MGE derivatives (Sussel et al., 1999), the analysis of striatal interneurons in this mutant has not been described.

In this work we describe our studies that investigated the origin of the four major types of striatal interneurons, and that demonstrates the essential role of the Nkx2.1, Dlx1, Dlx2, and Mash1 transcription factors in controlling their development. In addition, we also provide evidence that two different LIM-homeodomain transcription factors, $L h x 6$ and $L h x 7$, might control the develop- 
ment of distinct subtypes of striatal interneurons. In toto, these results begin to elucidate the pathway of transcription factors that control specification and differentiation of striatal interneurons.

\section{MATERIALS AND METHODS}

Animals. C57BL/J6 mice were used for the organotypic slice culture experiments and for immunohistochemical colocalization studies. In addition, mouse mutant strains with null alleles of $N k x 2.1$ (a gift of S. Kimura, National Cancer Institute, Bethesda, MD), Mash1 (Guillemot et al., 1993), and Dlx-1 and Dlx-2 (Qiu et al., 1997) were used for the immunohistochemical localization of striatal interneurons. These mutant strains were maintained by backcrossing to $\mathrm{C} 57 \mathrm{BL} / \mathrm{J} 6$ mice for at least 10 generations. For staging of the embryos, midday of the vaginal plug was considered as embryonic day 0.5 (E0.5). Mouse colonies were maintained at University of California, San Francisco in accordance with National Institutes of Health and UCSF guidelines.

Retrovirus preparation. The production of Moloney murine leukemia virus/vesicular stomatitis virus G (MMLV/VSV-G) pseudotyped retrovirus has been described in detail previously (Ory et al., 1996). Briefly, a replication-defective retroviral construct ( $\Delta \mathrm{U} 3$ nlxLacZ) encoding a nuclear-localizing $\beta$-galactosidase $(\beta$-gal) under the control of the human cytomegalovirus (HCMV) enhancer-promoter was cotransfected into a 293-derived packaging cell line. Viral supernatants were harvested and concentrated by ultracentrifugation. Viral pellets were resuspended in PBS, and aliquots of virus were stored at $-80^{\circ} \mathrm{C}$

Organotypic slice cultures. Organotypic slice cultures of embryonic mouse telencephalon were prepared as previously described (Anderson et al., 1997a). Briefly, embryos (E12.5-E16.5) were removed by cesarean section and decapitated. Brains were removed in ice-cold Krebs' buffer, $\mathrm{pH}$ 7.4, containing (in mM) $126 \mathrm{NaCl}, 2.5 \mathrm{KCl}, 1.2 \mathrm{NaH}_{2} \mathrm{PO}_{4}, 1.2 \mathrm{MgCl}_{2}, 2.5$ $\mathrm{CaCl}_{2}, 11$ glucose, and $25 \mathrm{NaHCO}_{3}$. Then the brains were embedded in $4 \%$ low melt point agarose (FMC Bioproducts, Rockland, MA), and $250-\mu \mathrm{m}$-thick coronal sections were cut on a vibratome and collected in ice-cold Krebs' buffer. The sections subsequently were transferred to sterile ice-cold Krebs' buffer (filtered Krebs' containing $10 \mathrm{~mm}$ HEPES, penicillin, streptomycin, and gentamycin). After $15 \mathrm{~min}$ the sections were transferred to polycarbonate culture membranes $(13 \mathrm{~mm}$ diameter, $8 \mu \mathrm{m}$ pore size; Corning Costar, Cambridge, MA) in organ tissue dishes containing $1 \mathrm{ml}$ of medium with serum (Gibco MEM with glutamine, $10 \%$ fetal calf serum, penicillin, and streptomycin). Subsequently, they were incubated for $1 \mathrm{hr}$ in a sterile incubator (at $37^{\circ} \mathrm{C}$ in $5 \% \mathrm{CO}_{2}$ ), after which the medium was change to Neurobasal/B-27 (Life Technologies, Gaithersburg, MD). Injections were performed immediately after this step. Retroviruses were pressure-injected focally onto the LGE or MGE by a pneumatic PicoPump (Narishige, Tokyo, Japan) through a glass micropipette. After incubation for various times the slices were fixed in $4 \%$ paraformaldehyde (PFA) in $0.1 \mathrm{M}$ PBS for $1 \mathrm{hr}$ at $4^{\circ} \mathrm{C}$ and processed for $\beta$-gal histochemistry or $\beta$-gal/NKX2.1 double immunohistochemistry as described below. In control experiments $2 \mu \mathrm{g} / \mu \mathrm{l}$ of cytochalasin-D (Sigma, St. Louis, MO) was added to the culture medium $12 \mathrm{hr}$ after the injections to inhibit cell migration.

$\beta$-Gal staining. $\beta$-Gal histochemistry was performed in free-floating sections at $37^{\circ} \mathrm{C}$ overnight in a solution containing $0.005 \% \mathrm{Na}$ deoxycholate, $0.01 \%$ Nonidet $\mathrm{P} 40,5 \mathrm{mM} \mathrm{K}_{4} \mathrm{Fe}(\mathrm{CN})_{6}, 5 \mathrm{~mm} \mathrm{~K} \mathrm{~K}_{3} \mathrm{Fe}(\mathrm{CN})_{6}, 2$ $\mathrm{mM} \mathrm{MgCl}_{2}$, and $0.8 \mathrm{mg} / \mathrm{ml}$ of 5-bromo-4-chloro-3-indolyl- $\beta$-Dgalactopyranoside (X-gal) in $10 \mathrm{~mm}$ Tris-HCl buffer (TB), $\mathrm{pH} 7.3$. Then the sections were rinsed in TB, fixed for $1 \mathrm{hr}$ in $4 \%$ PFA, dehydrated, and cleared in xylene. For $\beta$-gal/NKX2.1 double immunohistochemistry the organotypic slice cultures were fixed, cryoprotected in $30 \%$ sucrose in PBS, cut into $20 \mu \mathrm{m}$ sections, and mounted onto Superfrost Plus slides (Fisher Scientific, Pittsburgh, PA). Then the sections were preincubated in $5 \%$ normal goat serum (NGS), $1 \%$ bovine serum albumin (BSA), and $0.2 \%$ Triton X-100 (TX) in PBS for $30 \mathrm{~min}$ at room temperature; subsequently, they were incubated overnight at $4{ }^{\circ} \mathrm{C}$ in a cocktail of primary antisera diluted 1:1000 with 2\% NGS and $0.2 \%$ TX in PBS. Mouse anti- $\beta$-gal (Promega, Madison, WI) and rabbit anti-NKX2.1 (Biopat Immunotechnologies, Caserta, Italy) antisera were used. Sections were rinsed in PBS and incubated for $1 \mathrm{hr}$ in a cocktail of Alexa 488 goat anti-mouse and Alexa 594 goat anti-rabbit secondary antisera (Molecular Probes, Eugene, OR) diluted 1:200 in the same solution as the primary antisera. Washings were performed in PBS, and the sections were coverslipped with Prolong Antifade mounting medium (Molecular Probes). In all cases, NKX2.1 immunoreactivity was used to demarcate the mantle region of the MGE and the LGE.

Immunohistochemistry single labeling. E18.5 embryos, removed by caesarean section, and neonates were anesthetized by cooling and perfused with $4 \%$ PFA. Brains were removed and post-fixed for $3 \mathrm{hr}$, cryoprotected in $30 \%$ sucrose in PBS, and cut frozen in the transverse plane on a sliding microtome at $40-50 \mu \mathrm{m}$. Then free-floating sections were preincubated in $5 \%$ normal serum of the species in which the secondary antibody was raised, $1 \% \mathrm{BSA}$, and $0.3 \% \mathrm{TX}$ in $\mathrm{PBS}$ for $1 \mathrm{hr}$ at room temperature; subsequently, they were incubated with the primary antisera for $36 \mathrm{hr}$ at $4{ }^{\circ} \mathrm{C}$ in $2 \%$ normal serum and $0.3 \%$ TX in PBS. The following antibodies were used: rabbit anti-CB (Swant, Bellinzona, Switzerland), diluted 1:5000; rabbit anti-CR (Chemicon, Temecula, CA), diluted 1:5000; goat antiChAT (Chemicon), diluted 1:100; rabbit anti-NPY (Incstar, Stillwater,
MN), diluted 1:3000; rat anti-SOM (Chemicon), diluted 1:250; and rabbit anti-NOS (Zymed, San Francisco, CA), diluted 1:1000. Sections then were incubated in biotinylated secondary antibodies (Vector Laboratories, Burlingame, CA), diluted 1:200, and processed by the ABC histochemical method (Vector Laboratories). The sections were mounted onto Superfrost Plus slides (Fisher Scientific), dried, dehydrated, and coverslipped with Permount (Fisher Scientific). In each experiment the sections from homozygous mutants and their wild-type or heterozygous littermates were processed together. Primary antiserum omission controls and normal mouse, rabbit, and goat serum controls were used to confirm further the specificity of the immunohistochemical labeling. Labeled cells were plotted by using a system for image analysis (Openlab Improvision, UK). For counting the numbers of striatal interneurons in Nkx2.1 and Mash1 mutants, we analyzed two defined striatal levels in three independent experiments. Wild-type and mutant striatal sections were matched by using external anatomical references. At the rostral striatal level, equivalent cortical and septal levels were used as landmarks. At the caudal striatal level, equivalent regions of the hippocampus and preoptic area were used as landmarks. The mean striatal area $\left(\mathrm{mm}^{2} \pm\right.$ SEM) at the rostral section plane is $0.95 \pm 0.12$ for the wild-type and $1.1 \pm 0.16$ and $0.86 \pm 0.09$ for the Nkx2.1 and Mash1 mutants, respectively. At the caudal section plane the mean striatal area $\left(\mathrm{mm}^{2} \pm \mathrm{SEM}\right)$ is $0.79 \pm 0.08$ in wild-type mice and $0.85 \pm 0.12$ and $0.72 \pm 0.11$ in $N k \times 2.1$ and Mash1 mutant mice, respectively. Because the area surface of the striatum in Dlx1/2 mutant mice is relatively constant throughout the rostrocaudal extend of the nucleus, a single level was analyzed in three independent experiments. The cortex and septum were used as anatomical landmarks to match the rostrocaudal level from both wild-type and mutant sections. The mean striatal area $\left(\mathrm{mm}^{2} \pm \mathrm{SEM}\right)$ is $0.81 \pm 0.07$ for the wild-type and $0.23 \pm 0.03$ for the Dlx1/2 mutant. The mean diameter $(\mu \mathrm{m} \pm$ SEM) of striatal neurons is $9.22 \pm 0.89$ in wild-type and $9.32 \pm 0.58,9.36 \pm 0.68$, and $9.29 \pm 0.56$ in Nkx2.1, Mash1, and Dlx1/2 mutant mice, respectively.

Immunohistochemistry double labeling. Mice 3-4 weeks old were anesthetized with an overdose of chloral hydrate and perfused transcardially with $20 \mathrm{ml}$ of $0.9 \% \mathrm{NaCl}$, followed by $60 \mathrm{ml}$ of $4 \%$ PFA in PBS. The brains were removed, post-fixed for $2 \mathrm{hr}$ at $4^{\circ} \mathrm{C}$, cryoprotected, and sectioned frozen in the transverse plane on a sliding microtome at 30-40 $\mu \mathrm{m}$. Free-floating sections were preincubated in 5\% normal serum of the species in which the secondary antibody was raised, $1 \%$ BSA, and $0.4 \% \mathrm{TX}$ in PBS for $1 \mathrm{hr}$ at room temperature; subsequently, they were incubated in a cocktail of primary antisera for $36 \mathrm{hr}$ at $4^{\circ} \mathrm{C}$. The cocktail always includes a rabbit anti-NKX2.1 antiserum, diluted 1:1000 in 2\% normal serum and $0.4 \%$ TX in PBS, and one of the following antisera: mouse anti-CB (Sigma), diluted 1:1000; mouse anti-DARPP-32, diluted 1:15,000; mouse anti-CR (Chemicon), diluted 1:1000; goat anti-ChAT (Chemicon), diluted 1:100; sheep anti-NPY (Chemicon), diluted 1:1000; or rat anti-SOM (Chemicon), diluted 1:250. Then the sections were rinsed in PBS and incubated for $2 \mathrm{hr}$ in a cocktail of secondary antibodies diluted 1:200 in the same solution as the primary antisera. Alexa 488 goat anti-mouse and Alexa 594 goat anti-rabbit were used for NKX2.1 and CB, DARPP-32, CR, NPY, or SOM double labeling, whereas Alexa 488 goat anti-rabbit and Alexa 594 donkey anti-goat (Molecular Probes) were used for NKX2.1 and ChAT double labeling. After being rinsed in PBS, the sections were stained with $50 \mu \mathrm{g} / \mathrm{ml}$ of Hoechst 33342 (Molecular Probes), mounted, and coverslipped with Prolong Antifade mounting medium. Analysis of colocalization of NKX2.1 with striatal markers was performed in three defined striatal sectors (dorsomedial, dorsolateral, and ventral striatum; $0.5 \mathrm{~mm}^{2}$ each) in two sections at defined rostrocaudal levels of the striatum in a total of three mice. The percentage of double-labeled cells (e.g., NKX2.1-ChAT double-labeled/total ChAT neurons at the three rostrocaudal levels) is averaged for the three mice. The mean number ( \pm SEM) of neurons counted for each marker per animal is as follows: $\mathrm{CB}, n=327 \pm 7.3$; DARPP-32, $n=380.3 \pm 5.8$; ChAT, $n=148.7 \pm 11.6 ;$ PV,$n=65.3 \pm 6.9$; CR $n=42 \pm 4.7$; NPY, $n=187 \pm 13.3$; and SOM, $n=194.3 \pm 10.2$

NADPH-diaphorase (NADPHd) staining. NADPHd histochemistry was performed in free-floating sections at $37^{\circ} \mathrm{C}$ as previously described (Marín et al., 1998). Briefly, E18.5 embryos and neonates were anesthetized by cooling and were perfused with 4\% PFA. Brains were removed and post-fixed for $3 \mathrm{hr}$, cryoprotected in $30 \%$ sucrose in PBS, and cut frozen in the transverse plane on a sliding microtome at $40 \mu \mathrm{m}$. Then the freefloating sections were preincubated in a medium containing $1 \mathrm{~mm}$ $\beta$-NADPH (Sigma), $0.8 \mathrm{~mm}$ nitroblue tetrazolium (Sigma), and $0.06 \%$ TX in PBS at $37^{\circ} \mathrm{C}$ for $1-2 \mathrm{hr}$. After incubation the sections were rinsed thoroughly in PBS, mounted, and, after drying overnight, were coverslipped.

5-Bromo-2'-deoxyuridine (BrdU) labeling. Pregnant females were injected intraperitoneally with $40 \mathrm{mg} / \mathrm{kg}$ of BrdU (Sigma) and killed 30 min later, or gestation was continued to term. Embryos were removed by caesarean section and decapitated; their brains were removed and fixed in 4\% PFA in PBS overnight at $4^{\circ} \mathrm{C}$. Neonates were perfused as described above. In all cases the brains were cryoprotected in $30 \%$ sucrose, cut into $10 \mu \mathrm{m}$ sections, and mounted onto Superfrost Plus slides. Then the sections were preincubated in 5\% NGS, $1 \%$ BSA, and $0.2 \%$ TX in PBS for $30 \mathrm{~min}$ at room temperature; subsequently, they were incubated overnight at $4{ }^{\circ} \mathrm{C}$ in a rabbit antiserum against NKX2.1 diluted 1:500 in $2 \%$ NGS and $0.2 \%$ TX in PBS. After being rinsed in PBS, the sections were post-fixed in 4\% PFA in PBS for $20 \mathrm{~min}$ and subsequently were incubated with $2 \mathrm{~N} \mathrm{HCl}$ in PBS 


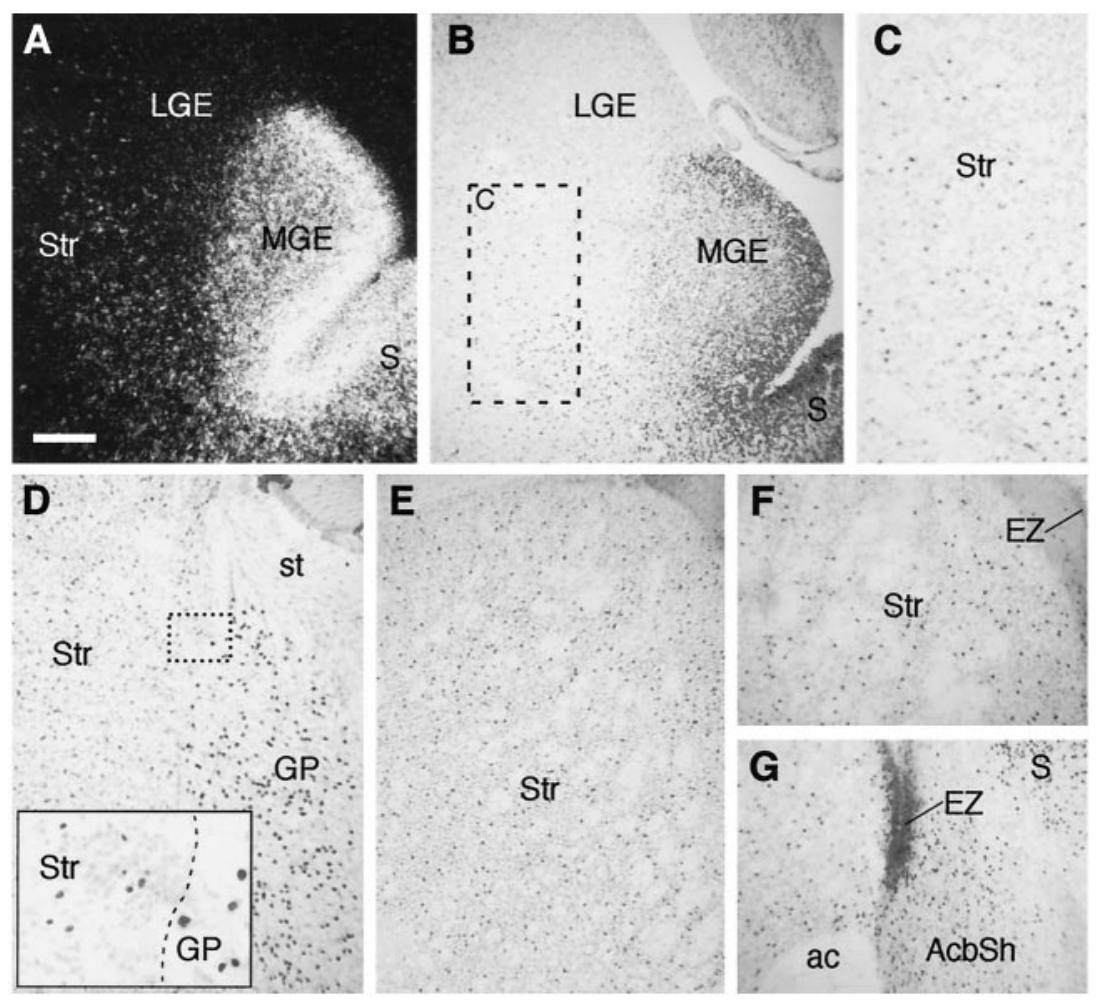

Figure 1. Developmental expression of $N k x 2.1$ RNA and protein in the basal telencephalon. $A$, RNA in situ hybridization analysis of $N k x 2.1$ expression in a coronal section of the basal telencephalon at E14.5. $B$, NKX2.1 protein distribution in an adjacent section to that shown in $A$. $C, \mathrm{~A}$ higher magnification image of the outlined boxed region in $B . D-G$, Expression of NKX2.1 in coronal sections through the telencephalon of the mouse at P18. ac, Anterior commissure; AcbSh, shell of the nucleus accumbens; EZ, ependymal zone; $G P$, globus pallidus; $L G E$, lateral ganglionic eminence; $M G E$, medial ganglionic eminence; $S$, septum; st, stria terminalis; Str, striatum. Scale bar: $A, B, F, G$, $200 \mu \mathrm{m} ; C, 100 \mu \mathrm{m} ; D, E, 300 \mu \mathrm{m}$. for $20 \mathrm{~min}$ at $37^{\circ} \mathrm{C}$. Then the sections were rinsed in PBS and incubated 2 hr in a mouse anti-BrdU antibody (Chemicon) diluted 1:200 as before After being rinsed in PBS, the sections were incubated in a cocktail of Alexa 488 goat anti-mouse and Alexa 594 goat anti-rabbit secondary antibodies diluted $1: 200$ in the same solution as the primary antisera. Washings were performed in PBS, and the sections were stained with Hoechst and coverslipped as above.

In situ $R N A$ hybridization. In situ hybridization experiments were performed by using ${ }^{35} \mathrm{~S}$ riboprobes on $10 \mu \mathrm{m}$ frozen sections as described previously (Bulfone et al., 1993). The cDNA probes used in this study were Nkx2.1 (Shimamura et al., 1995), Lhx6 and Lhx7 (kindly provided by V. Pachnis, National Institute for Medical Research, London, UK), and ENK (kindly provided by C. Gerfen, National Institute of Mental Health, Bethesda, MD).

\section{RESULTS}

\section{NKX2.1 expression in the basal telencephalon}

$N k x 2.1$ expression is first detectable in the mouse basal telencephalon at the 11 somite stage, at approximately E8.75 (Shimamura et al., 1995). Between E10.5 and E11.5 Nkx2.1 is strongly expressed in several regions within the basal telencephalon/medial ganglionic eminence (MGE), part of the septum, anterior entopeduncular area (AEP), and preoptic area (POa) (Price et al., 1992; Kohtz et al., 1998; Sussel et al., 1999) (see also Fig. 10 $A$ ). In these structures $N k \times 2.1$ is expressed in both proliferative and postmitotic cells (Sussel et al., 1999). Conversely, Nkx2.1 expression is not found at these stages in cells of the lateral ganglionic eminence (LGE), a proliferative zone that is thought to give rise to the striatum (Deacon et al., 1994; Anderson et al., 1997a). From E13.5 the immature basal telencephalic nuclei that express $N k \times 2.1$ are clearly recognizable and include the globus pallidus, ventral pallidum, entopeduncular nucleus, substantia innominata/basal magnocellular region, anterior part of the bed nucleus of the stria terminalis, and part of the septum (Puelles et al., 1999; Sussel et al., 1999).

Here we extended previous analyses by examining the expression of NKX2.1 protein in detail. In the telencephalon NKX2.1 expression appeared to be restricted primarily to the cell nucleus (Fig. 1). From E14.5, NKX2.1 expression is found in scattered cells of the striatum (Fig. $1 A-C$ ), despite the fact that it is not expressed in the proliferative zones of the LGE at the time when striatal neurons are born (mostly between E11 and E16 in the mouse; see references in Semba et al., 1988; Sadikot and Sasseville, 1997). Thus
BrdU injections $30 \mathrm{~min}$ before death at different developmental stages (E12.5-E16.5) double-label NKX2.1 ${ }^{+}$cells in the MGE, but not in the LGE (data not shown).

As development proceeds, NKX2.1 is maintained in a subpopulation of striatal cells. In the postnatal brain $\mathrm{NKX} 2.1^{+}$cells are found not only in the pallidal components of the basal ganglia (Fig. $1 D$ ) but also in scattered cells within the dorsal and ventral subdivisions of the striatum (Fig. $1 D-G$ ). Immunoreactivity for NKX2.1, however, is always stronger in the nuclei of pallidal than of striatal neurons. In summary, NKX2.1-expressing cells are present in the striatum, despite evidence that progenitor cells of this region (LGE) do not express this protein.

\section{NKX2.1 striatal cells migrate from the MGE and POa/AEP}

Because the proliferative zone of the striatum (LGE) does not express NKX2.1 before E16.5, we wondered whether this population of striatal cells arrives via a tangential migration from the MGE. Our previous study, using DiI labeling of MGE cells, suggested that there is a tangential migration from the MGE to the LGE (Sussel et al., 1999). However, that study did not resolve several important questions, including the origin of the progenitors that give rise to the migrating cells and their eventual phenotype. In addition, it is also possible that striatal $\mathrm{NKX} 2.1^{+}$cells derive from the LGE, but, in contrast to the cells originated in the MGE, they start to express NKX2.1 only when they become postmitotic. To distinguish between these possibilities, we studied the origin of striatal $\mathrm{NKX} 2.1^{+}$cells by infecting telencephalic slices with replication-incompetent retroviruses encoding the marker $\beta$-galactosidase (see Materials and Methods). These viruses can integrate only into mitotically active cells, and thus this method enables us to follow the movements of progenitor cells at different times after their infection.

Retroviral vectors were injected into either the VZ/SVZ of the LGE or the MGE in coronal slices from the telencephalon of E12.5-E16.5 mice (Fig. 2A). After $20 \mathrm{hr}$ the infected cells were always located within a radius of $100-400 \mu \mathrm{m}$ from the injection site $(n=9$ of 9 ; Fig. $2 B-D)$, suggesting that retroviral particles do 

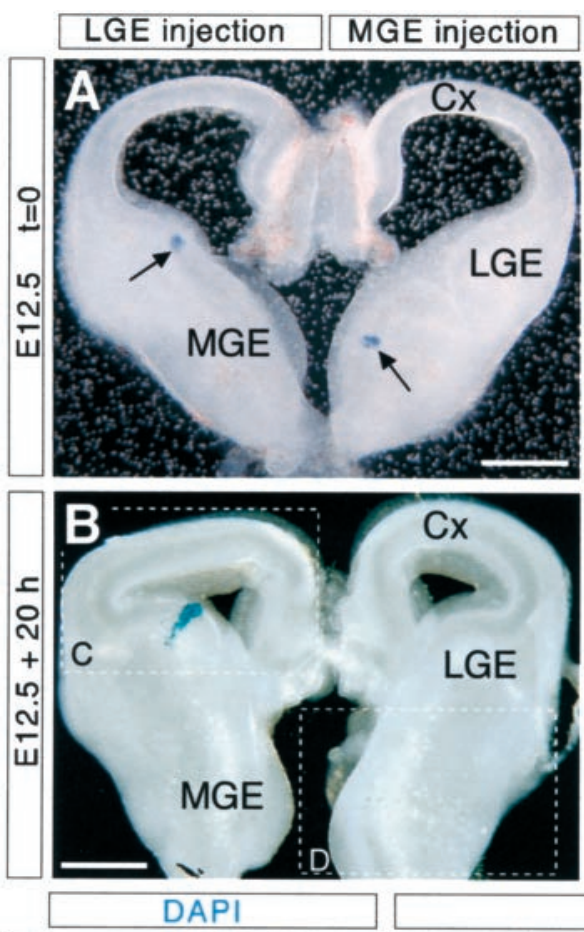

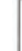
$H$, Higher magnification images of the outlined boxed regions in $E$ and $F$, respectively. Note that whereas both radially ( $a r-$ rowhead) and tangentially (arrows) migrating cells are observed after injection in the LGE $(E, G)$, most migrating cells migrate radially after MGE injection at this age $(F, H) . I-P$, A large number of $\beta$-gal ${ }^{+}$cells migrating from the MGE to the striatum are $\mathrm{NKX} 2.1^{+}(N-P)$, whereas none of the cells is NKX2.1 after retroviral injection in the LGE (I$L)$. I, $M$, DAPI-stained sections $(10 \mu \mathrm{m})$ obtained from a $250 \mu \mathrm{m}$ coronal slide through the telencephalon of an E14.5 mouse after retroviral injection into the LGE (star, $I$ ) or the MGE (star, $M$ ) and 70 $\mathrm{hr}$ in culture. $J, K, N, O$, Higher magnification images of the outlined boxed regions in $I$ and $M$, respectively. $L, P$, Higher magnification images of the outlined boxed regions in $J, K, N$, and $O$, respectively. Arrows point to double-labeled cells, whereas arrowheads show single $\beta$-gal cells. Cx, Cortex; GP, globus pallidus; $L G E$, lateral ganglionic eminence; $M G E$, medial ganglionic eminence; Str, striatum. Scale bars: $A, B, E, F, 400 \mu \mathrm{m} ; C, D, G, H$, $300 \mu \mathrm{m} ; I, M, 200 \mu \mathrm{m} ; J, K, N, O, 100 \mu \mathrm{m}$; $L, P, 40 \mu \mathrm{m}$

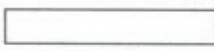

NKX2.1 $\beta$-gal

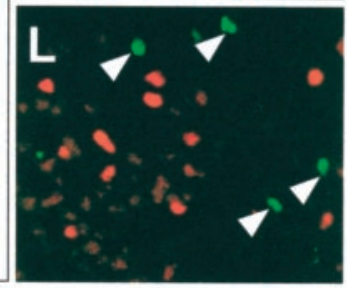

LGE injection
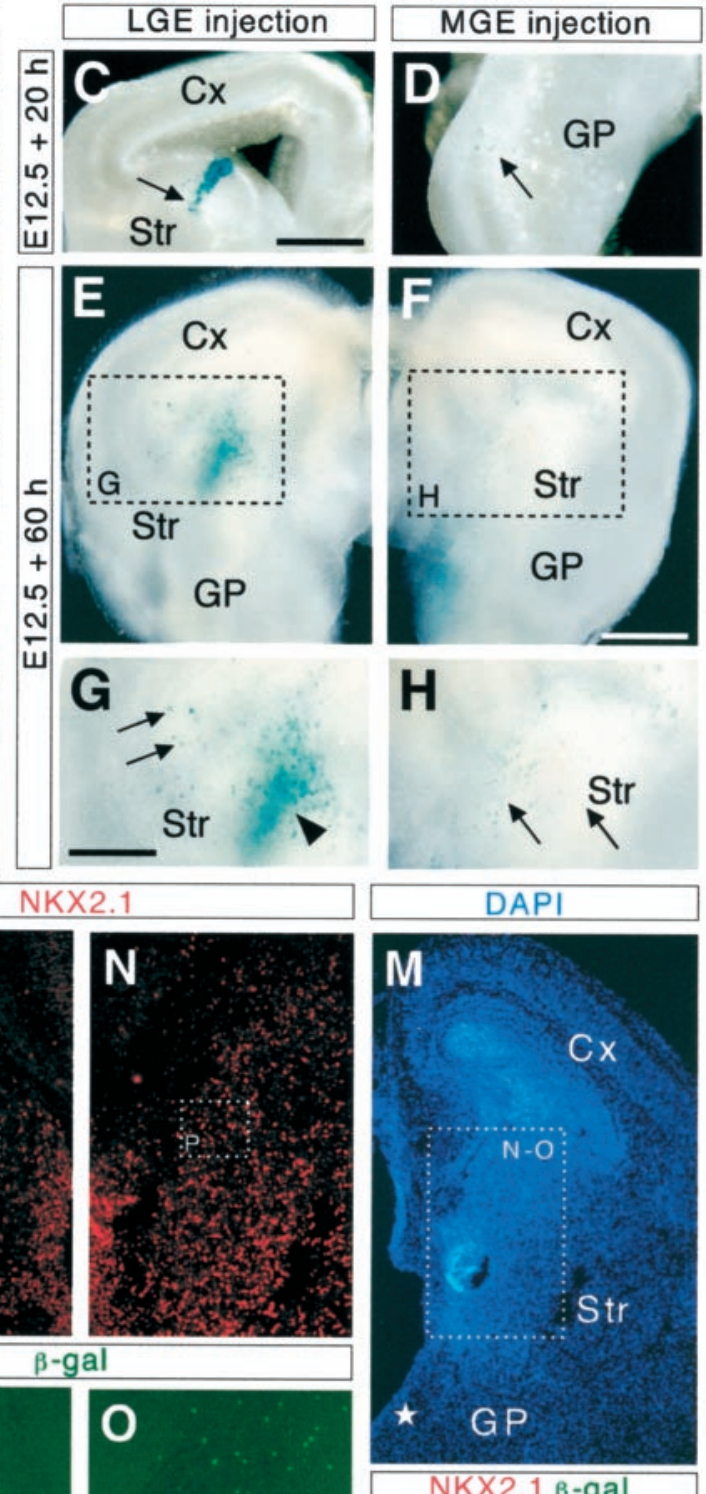
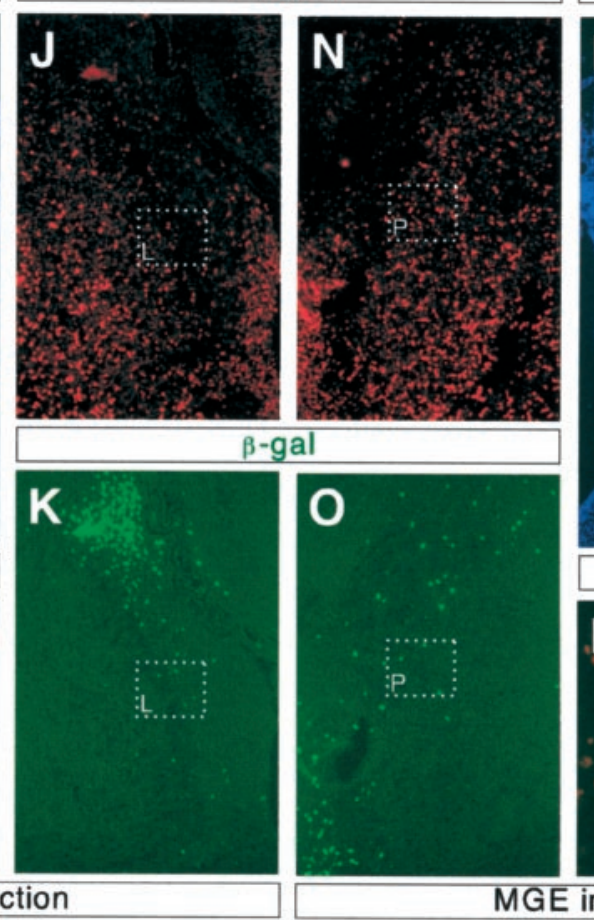

MGE injection

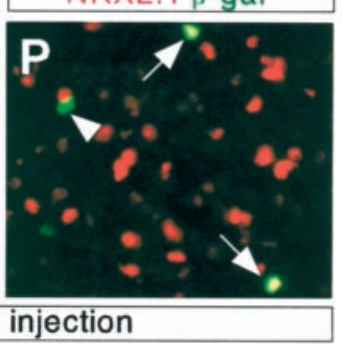

not diffuse passively between different proliferative zones. By $60 \mathrm{hr}$ the cells were detected outside the proliferative zones, and their number and distance from the injection site increased with time (Fig. $2 E-H)$. Blocking cell migration by the addition of cytochalasin-D $(0.5-1 \mathrm{mg} / \mathrm{ml})$ resulted in no $\beta$-gal ${ }^{+}$cells outside the injection site ( $n=8$; data not shown).

When retroviral particles were injected into the MGE, $\beta$-gal ${ }^{+}$ cells were observed to migrate into the mantle of the striatum at all stages that were examined (E12.5, E13.5, E14.5, and E16.5; $n=10$ of 10; Fig. 2F, H,K; data not shown). Usually, between 50 and 100 cells were labeled per experiment. Approximately $50 \%$ of the striatal $\beta$-gal ${ }^{+}$cells derived from the MGE were also positive for NKX2.1 (Fig. 2I-L). Moreover, viral injections into the adjacent POa/AEP (ventral to the MGE) at E12.5 also double-labeled NKX2.1 cells in the striatal mantle ( $n=3$ of 5; data not shown). In contrast, none of the $\beta$-gal ${ }^{+}$cells derived from the LGE expressed NKX2.1 at any of the stages that were examined ( $n=14$ of 14; Fig. $2 M-P)$. Taken together, these results suggest that striatal cells expressing NKX2.1 derive primarily from the MGE, although some NKX2.1 cells also originate in the adjacent POa/AEP.

\section{NKX2.1 is expressed in most striatal interneurons}

Because the mammalian striatum contains several cell types with different functional roles (Kawaguchi et al., 1995; Kawaguchi, 1997), we analyzed the expression of NKX2.1 in the distinct subtypes of striatal cells. We performed double-labeling experiments during the third postnatal week in the mouse, when the neurochemical characteristics of the striatum begin to resemble those of adults (Liu and Graybiel, 1992; Schlösser et al., 1999). 

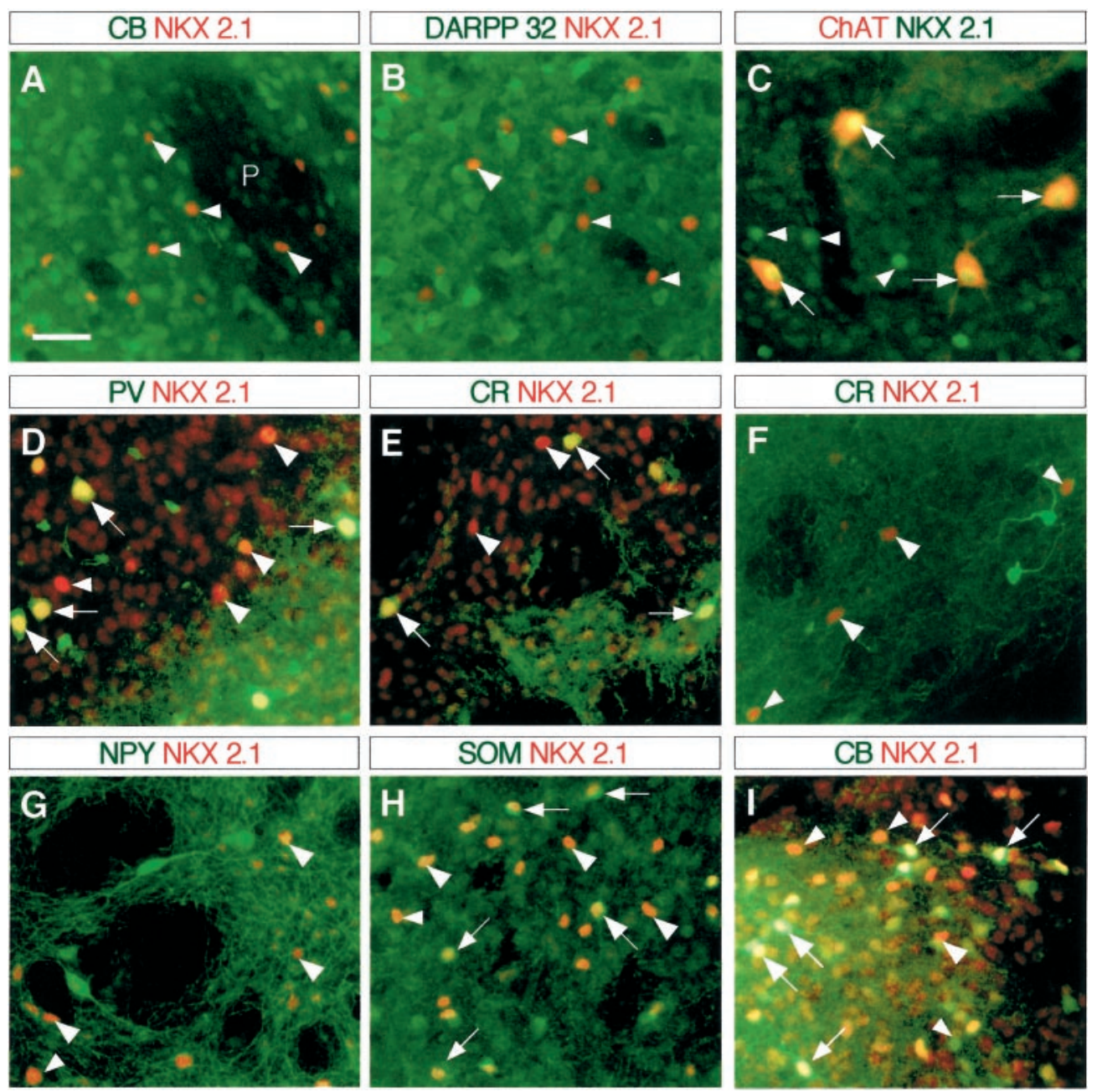

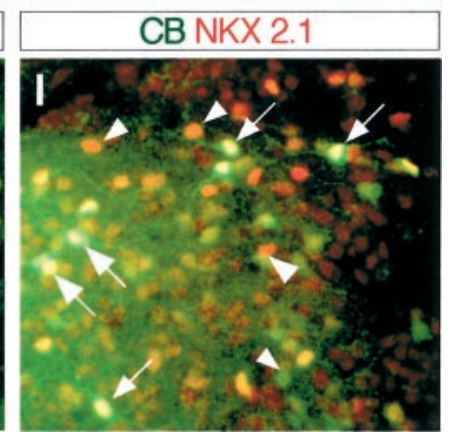

Figure 3. NKX2.1 is expressed in most striatal interneurons $(C-I)$, but not in striatal projection neurons $(A, B)$. Shown is colocalization of $\mathrm{NKX} 2.1$ and $\mathrm{CB}(A, I)$, DARPP32 $(B)$, ChAT $(C), \mathrm{PV}(D), \mathrm{CR}$ $(E, F), \mathrm{NPY}(G)$, or $\operatorname{SOM}(H)$ in the striatum of P18 mice. Arrows show double-labeled cells, whereas arrowheads indicate cells expressing only NKX2.1. $P$, Patch. Scale bar for $A-I, 40 \mu \mathrm{m}$.
First, we used CB immunohistochemistry to identify striatal projection neurons. $\mathrm{CB}$ is a calcium-binding protein that is expressed predominantly in medium-sized spiny neurons of the striatal matrix (Gerfen, 1992). Double-labeling experiments revealed that the medium-sized $\mathrm{CB}^{+}$neurons of the striatum do not express NKX2.1 (Fig. 3A). In addition, we analyzed the expression of NKX2.1 in striatal neurons containing DARPP-32. DARPP-32 is a D1 receptor-associated protein found in striatal projection neurons, including both substance $\mathrm{P}$ and enkephalin-containing projection neurons in the patch and matrix compartments, and is virtually absent from striatal interneurons (Anderson and Reiner, 1991). No NKX2.1 was detected in DARPP- $32^{+}$striatal neurons (Fig. 3B).

Double labeling revealed that all cholinergic striatal interneurons, as identified by the presence of the synthetic enzyme ChAT, are labeled for NKX2.1 also (Fig. 3C). In fact, all ChAT ${ }^{+}$neurons in the telencephalon are labeled with NKX2.1 (data not shown). Like the cholinergic neurons, all $\mathrm{PV}^{+}$striatal interneurons were found to contain NKX2.1 (Fig. 3D). In addition, the vast majority of $\mathrm{CR}^{+}$striatal interneurons also was labeled for NKX2.1 (94.2 \pm $1.2 \%$; Fig. $3 E$ ), although a small proportion of the $\mathrm{CR}^{+}$neurons in the striatum does not contain NKX2.1 at this age (Fig. $3 F$ ).

In contrast to the cholinergic, $\mathrm{PV}^{+}$, or $\mathrm{CR}^{+}$interneurons, $\sim 90 \%$ of striatal interneurons expressing SOM, NPY, and NOS do not express NKX2.1 at postnatal day 18 (P18) (arrowheads in Fig. $3 G, H)$. We found that only $\sim 10 \%$ of the $\mathrm{SOM}^{+}$or $\mathrm{NPY}^{+}$cells were immunolabeled for NKX2.1 (13.4 \pm 1.4\% for SOM; $11.3 \pm$ $1.7 \%$ for NPY; arrows in Fig. $3 H$; data not shown). Most of these cells were located in the ventral striatum, although a few doublelabeled cells also were found in the dorsal striatum.

In addition to its expression in projection neurons of the matrix,
$\mathrm{CB}$ also is found in a small subpopulation of striatal NOS interneurons (Bennett and Bolam, 1993; Kubota and Kawaguchi, 1993). These $\mathrm{CB}^{+}$neurons are larger and more intensely stained than the striatal projection neurons and are distributed in both the patch and the matrix compartments (Kiyama et al., 1990; Bennett and Bolam, 1993; Kubota and Kawaguchi, 1993). In our double-labeling experiments we found that a small number of $\mathrm{CB}^{+}$neurons contained NKX2.1 (arrows in Fig. 3I). As in the case of the NPY/ $\mathrm{SOM} / \mathrm{NOS}$ cells immunolabeled for $\mathrm{NKX} 2.1$, the $\mathrm{CB}^{+}$neurons containing NKX2.1 were located primarily in the ventral striatum, suggesting that they actually represent a subpopulation of the striatal interneurons containing SOM, NPY, and NOS.

To evaluate the relationship between NKX2.1 localization and interneuronal phenotype in the striatum further, we performed similar double-labeling experiments at earlier times of development. At $\mathrm{P} 0$ the number of $\mathrm{SOM}^{+}, \mathrm{NPY}^{+}$, or $\mathrm{NOS}^{+}$neurons that also contain NKX2.1 is substantially higher than at P18, in particular at rostral striatal levels (data not shown). Nevertheless, most $\mathrm{SOM}^{+}$ or $\mathrm{NPY}^{+}$striatal neurons do not contain NKX2.1 at this age.

The results from these double-labeling experiments (Fig. 3) combined with the cell migration assay (see Fig. 2) support the notion that striatal cholinergic $\left(\mathrm{ChAT}^{+}\right), \mathrm{PV}^{+}$, and $\mathrm{CR}^{+}$interneurons derive from the MGE and that NKX2.1 might play an important role in their development. In addition, at least a subpopulation of the NPY/SOM/NOS striatal interneurons also may derive from the MGE. It is not clear, however, whether all striatal interneurons containing SOM, NPY, and NOS may derive from the MGE but downregulate the expression of NKX2.1 as they progressively differentiate. To clarify this problem, we analyzed the distribution of striatal interneurons in $N k x 2.1$ mutant mice. 


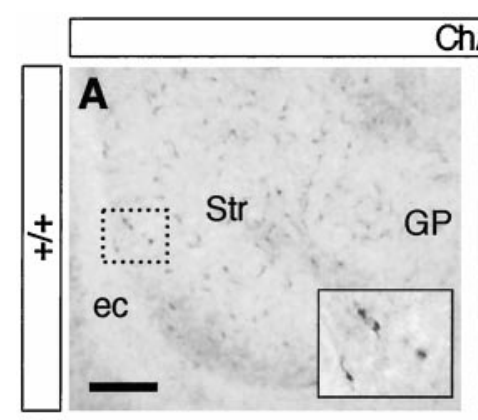

\section{ChAT}
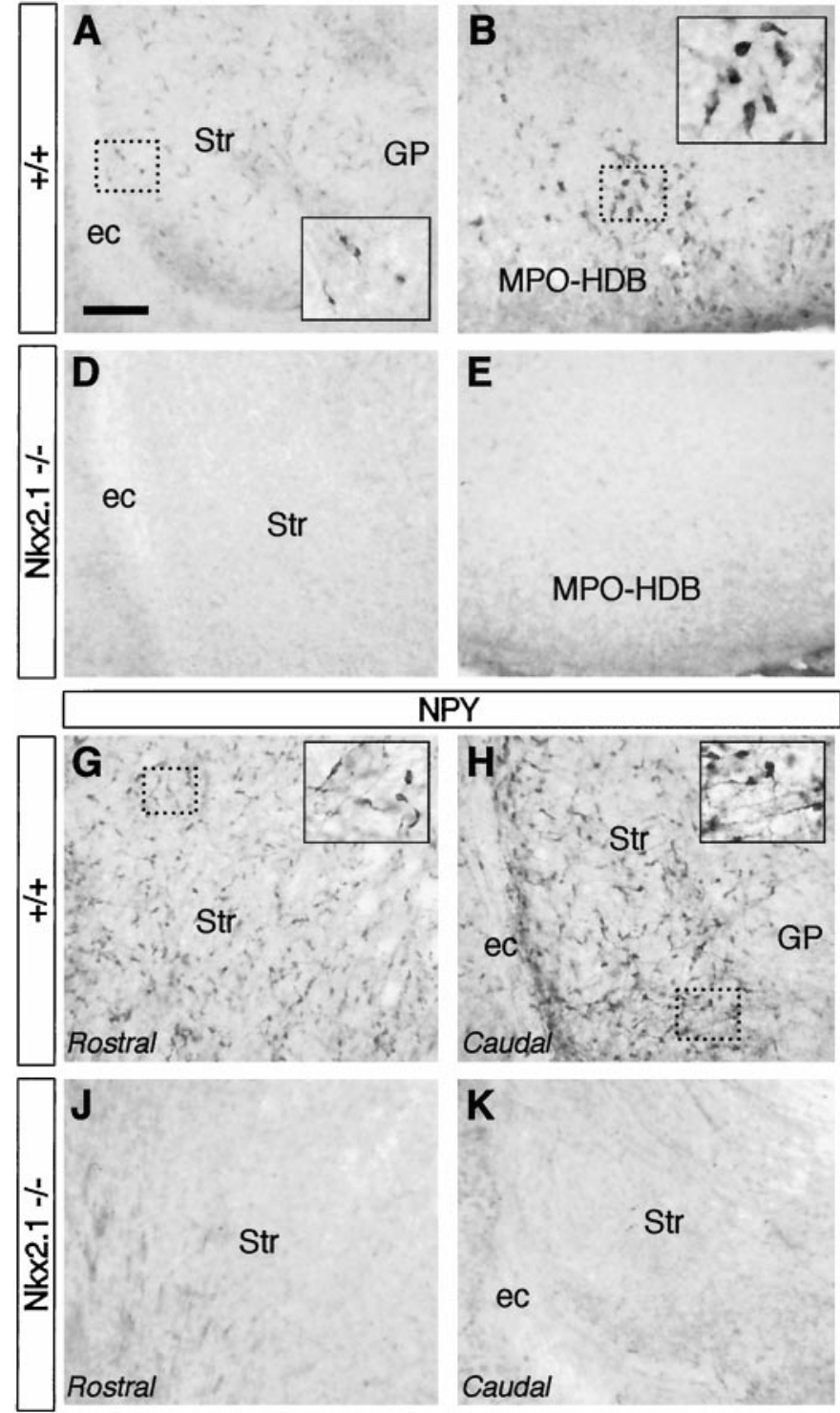
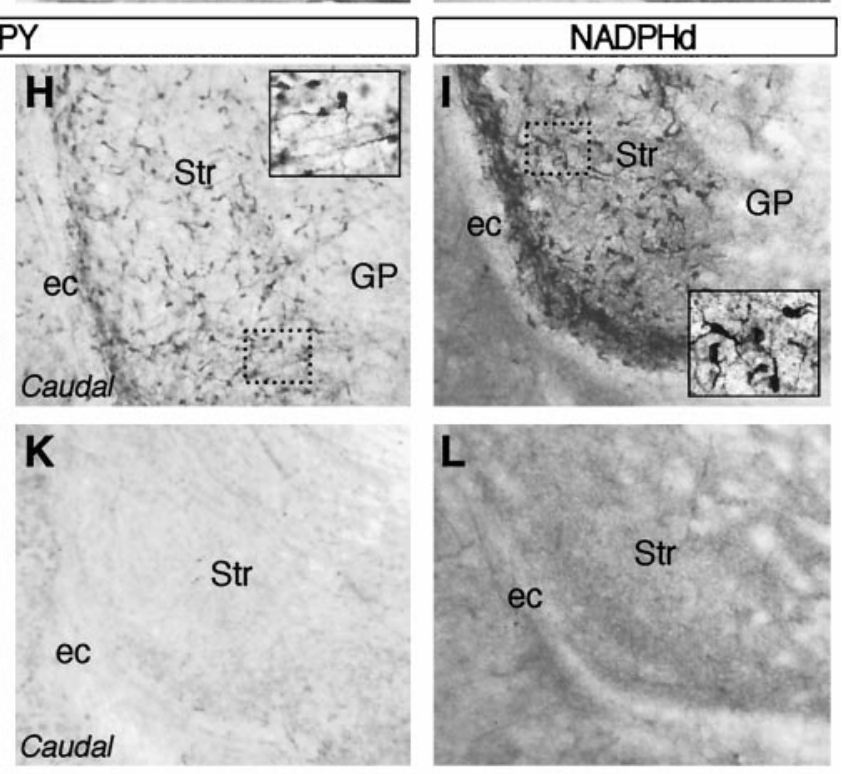
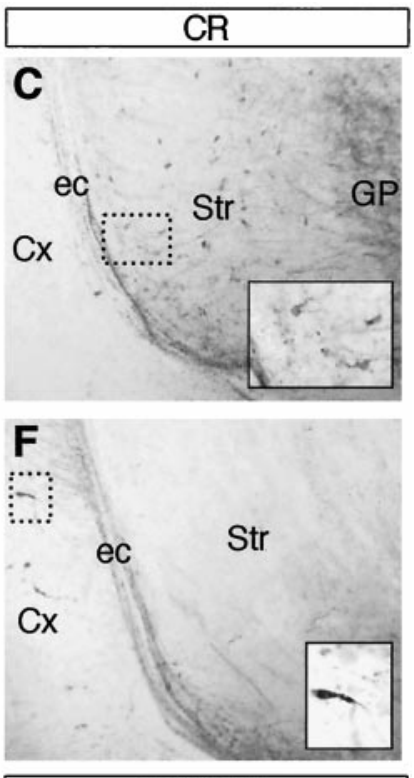
nal band; Str, striatum. Scale bar for $A-L$ $100 \mu \mathrm{m}$.

\section{Nkx2.1 mutants are defective in striatal interneurons}

In mice deficient for $N k \times 2.1$, pallidal structures are not detectable and the cerebral cortex has reduced numbers of interneurons (Sussel et al., 1999). Because homozygous mutants die immediately after birth, we analyzed the expression of interneuronal markers in the striatum at E18.5. Although at this age several markers are either not cell type-specific (e.g., CB) (Liu and Graybiel, 1992) or are not expressed (PV; Schlösser et al., 1999), we were able to determine that cholinergic $\left(\mathrm{ChAT}^{+}\right), \mathrm{CR}^{+}$, and $\mathrm{SOM} / \mathrm{NPY} /$ $\mathrm{NOS}^{+}$interneurons are either eliminated or severely reduced in the $N k \times 2.1$ mutants. $\mathrm{ChAT}^{+}$interneurons were not found at any rostrocaudal level in the striatum (compare Fig. $4 A, D$ with $5 A$ ) nor in any region of the telencephalon, including the magnocellular nucleus, horizontal and vertical limbs of the diagonal band of Broca, medial septum, or the medial preoptic region (Fig. $4 B, E$; data not shown). $\mathrm{CR}^{+}$striatal interneurons were reduced severely at caudal striatal levels (approximately sixfold reduction; Figs. $4 C, F, 5 A$ ) although some $\mathrm{CR}^{+}$cells were present at rostral striatal levels (Fig. 5A). Finally, SOM/NPY/NOS-immunoreactive cells are missing almost completely from the $N k x 2.1$ mutant striatum (compare Figs. $4 G, H, J, K$ and $5 A$ ); when present, there would be two or three immunoreactive, abnormally large, and brightly stained cells in the ventral striatum (data not shown). In addition, neurons expressing NADPH-diaphorase (NADPHd), which is a marker of the SOM/NPY/NOS ${ }^{+}$interneurons, were not found in the mutant striatum (see Fig. 4I,L). Thus, at E18.5 the $N k \times 2.1$ mutants appear to lack most striatal interneurons.

\section{Striatal interneurons are reduced in Mash1 mutants}

Mash1 is a basic helix-loop-helix transcription factor gene that is required for the development of subsets of neurons in the peripheral nervous system and CNS (Guillemot et al., 1993; Sommer et al., 1995; Cau et al., 1997; Hirsch et al., 1998; Casarosa et al., 1999). In the telencephalon Mash1 is expressed in the proliferative zones of the LGE and the MGE (Lo et al., 1991; Guillemot and Joyner, 1993; Porteus et al., 1994; Torii et al., 1999) (see also Fig. 10B). Mice lacking Mash1 have a very small MGE (Casarosa et al., 1999; Horton et al., 1999). Thus, if the MGE is the source of most striatal interneurons, we hypothesized that there would be a reduction in their number in Mash1 mutants.

We analyzed the expression of striatal interneuronal subtype markers at P0, because Mash1 homozygous mutant mice die within hours after birth. Mash1 mutants have a severe reduction of NKX2.1 ${ }^{+}$striatal neurons (approximately threefold reduction; Figs. $5 B, 6 A, D)$. In line with these results, the number of cholinergic neurons in the striatum was reduced severely in Mash1 mutants (approximately sixfold reduction; Figs. $5 B, 6 B, E$ ), as it was in other basal telencephalic regions ( $\sim 10$-fold reduction; Figs. $5 B$, 

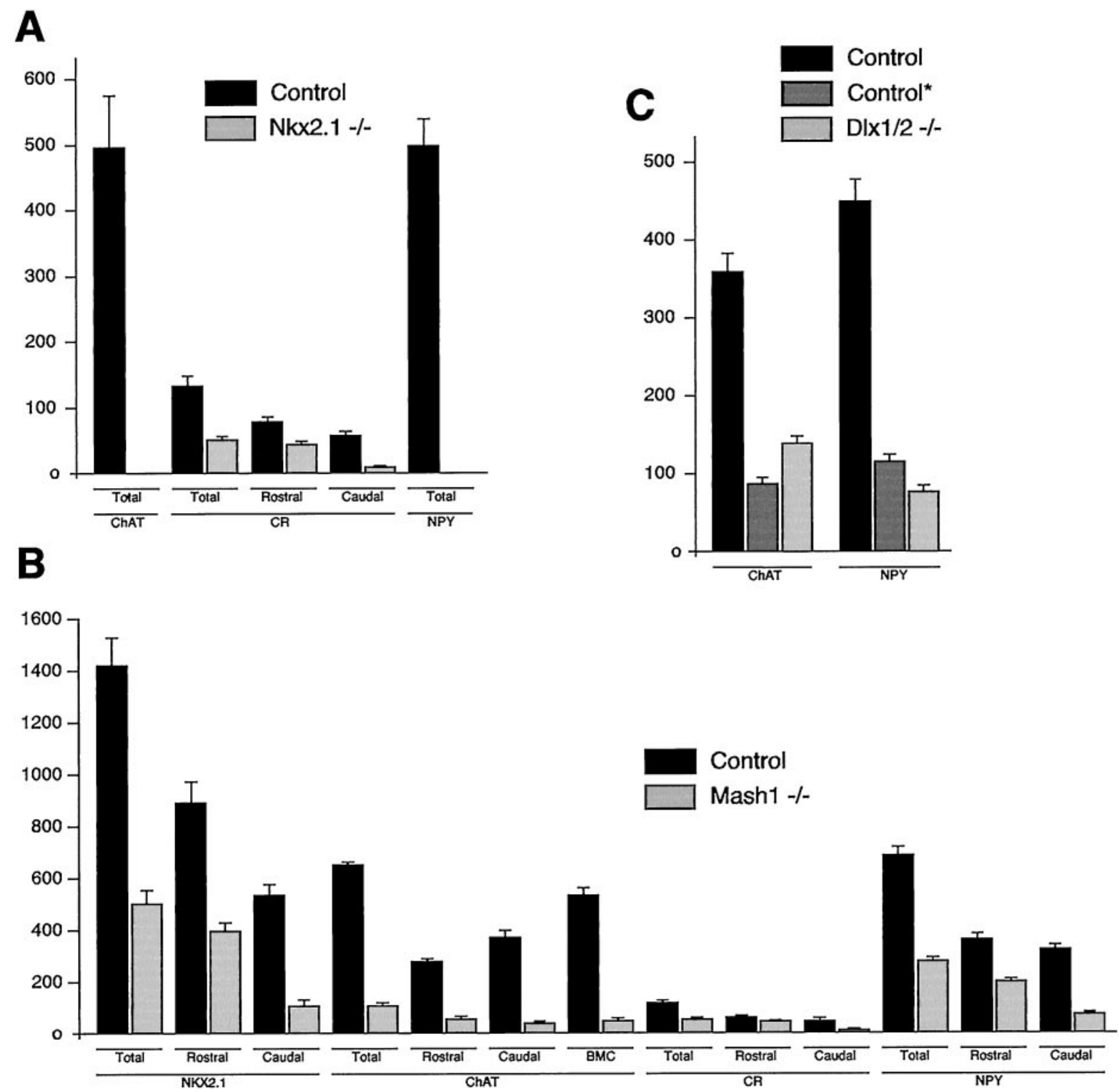

Figure 5. Reduction of different striatal interneuron subtypes in E18.5 Nkx2.1 $1^{-1-}$ fetuses $(A)$ and P0 Mash $1^{-1-}(B)$ and Dlx1/2 ${ }^{-1-}(C)$ newborns. Histograms show averages \pm SEM of the numbers of specific types of striatal interneurons. In $A$ and $B$ the cells were counted in two defined sections of the striatum (rostral and caudal) in three independent experiments in each case. Total represents the collective consideration of both rostral and caudal sections. In $C$ the cells were counted in a single striatal level in three independent experiments. In Control* we have taken into account the fourfold reduction in striatal surface area in the Dlx1/2 mutants (see Materials and Methods) by dividing the number of striatal interneurons in the wild-type striatum by four. $B M C$, Basal magnocellular complex.

$6 C, F$; data not shown). In addition, CR-immunoreactive cells are missing almost completely from the caudal striatum in Mash1 mutants, although a few CR cells are present in the rostral striatum (Figs. 5B, 6G,J). Finally, the number of striatal SOM/NPY/NOS/ NADPHd ${ }^{+}$interneurons also was reduced in Mash1 mutants (Fig. $5 H, I, K, L$; data not shown). The reduction of NPY/SOM/NOS/ NADPHd, as estimated via the number of $\mathrm{NPY}^{+}$neurons, was more prominent at caudal $(\sim 4.5$-fold reduction; Figs. $5 B, 6 H, K)$ than at rostral levels (approximately twofold reduction; Figs. $5 B$, $6 I, L)$. These results suggest that the number of neurons that adopt an interneuronal phenotype in the striatum is proportional to the number of $N k x 2.1$ neurons that become postmitotic in the ventral telencephalon.

The results from the colocalization studies, together with the data of the expression of striatal interneuronal markers in $N k \times 2.1$ and Mash1 mutants, strongly suggest that most striatal interneurons derive from the MGE/Nkx2.1 region. Furthermore, most ChAT, $\mathrm{CR}$, and PV striatal interneurons maintain the expression of NKX2.1 into adulthood, whereas most NPY/SOM/NOS interneu- rons do not. These results suggest that most NPY/SOM/NOS striatal interneurons derive from the MGE/Nkx2.1 region, but they downregulate the expression of NKX2.1 shortly after leaving the proliferative zone of the MGE. As described in the next section, the analysis of striatal interneurons in Dlx1/2 double mutants supports this hypothesis.

\section{DIx1/2 mutants provide evidence that striatal $\mathrm{NPY}^{+} / \mathrm{NKX}^{2.1^{-}}$interneurons are derived from the MGE}

$D l x-1$ and $D l x-2$ are homeobox transcription factor genes that are expressed in the proliferative zones of the LGE and MGE (Bulfone et al., 1993; Eisenstat et al., 1999) (see also Fig. 10C). Mice homozygous for a deletion of both genes (Dlx1/2 mutants) have a time-dependent block in striatal differentiation, resulting in the accumulation of late-born LGE neurons within the proliferative zone (Anderson et al., 1997a). In addition, a similar defect may occur in the MGE, as judged by the expression of NKX2.1 at P0. In the telencephalon of control mice the $\mathrm{NKX} 2.1^{+}$cells are located primarily in part of the septum, globus pallidus, ventral 

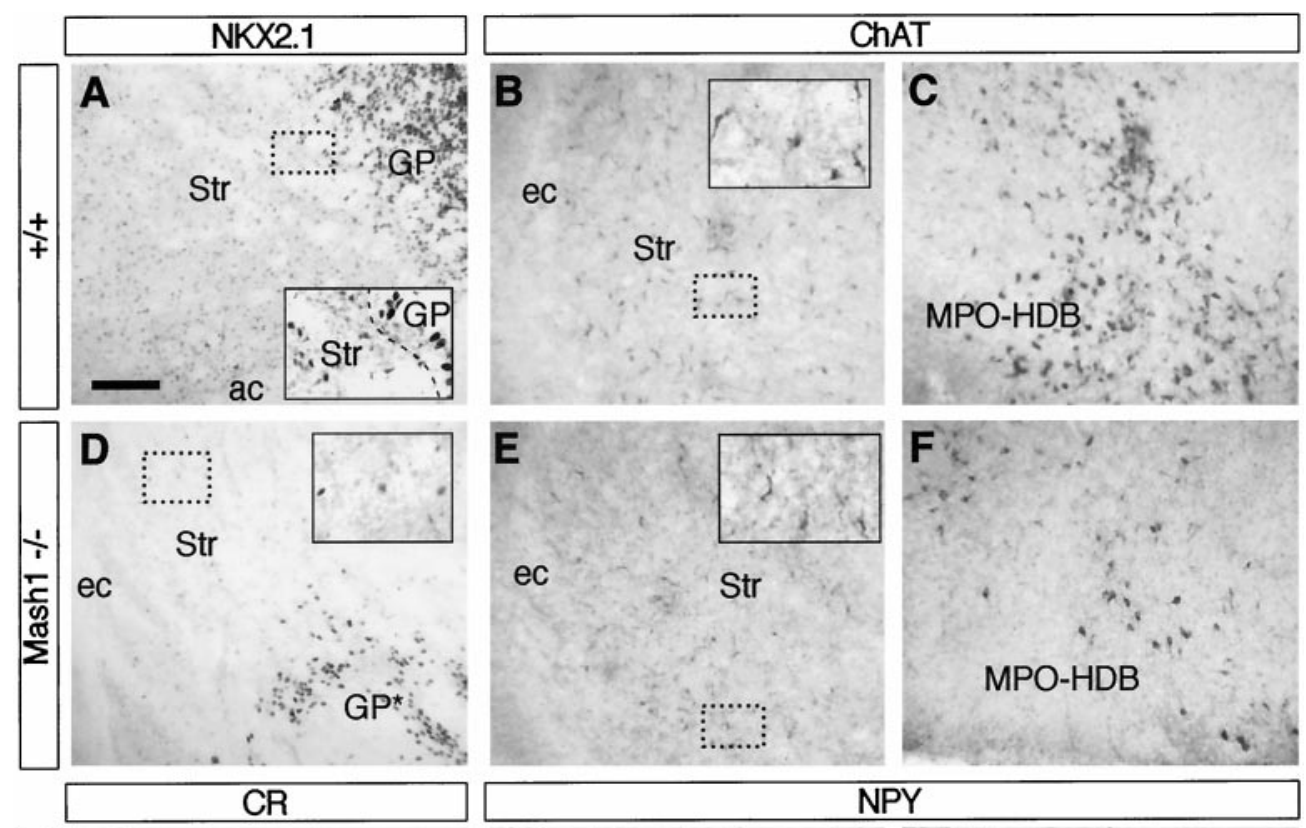

Figure 6. Reduction of striatal interneurons in Mash 1 mutants. $A-C, G-I$, Coronal sections through the telencephalon of P0 wild-type pups showing NKX2.1 $(A)$, ChAT $(B, C)$, CR $(G)$, and NPY immunoreactivity $(H, I)$ in the rostral striatum $(H)$, caudal striatum $(A, B, G-I)$, and basal telencephalon $(C) . D-F, J-L$, Coronal sections through the telencephalon of P0 Mash1 ${ }^{-1-}$ pups showing reduction of NKX2.1 $(D)$, ChAT $(E, F)$, CR $(J)$, and NPY immunoreactivity $(K, L)$ in the rostral striatum $(K)$, caudal striatum $(D, E, J$, $L$ ), and basal telencephalon $(F)$. Insets in $A, B, D, E, G, J$ show higher magnification images of neurons from the outlined boxed regions. $C x$, Cortex; ec, external capsule; $G P$, globus pallidus; $G P^{*}$, mutant GP; $M P O-H D B$, medial preoptic regionhorizontal limb of the diagonal band; Str, striatum. Scale bar for $A-L, 100 \mu \mathrm{m}$.
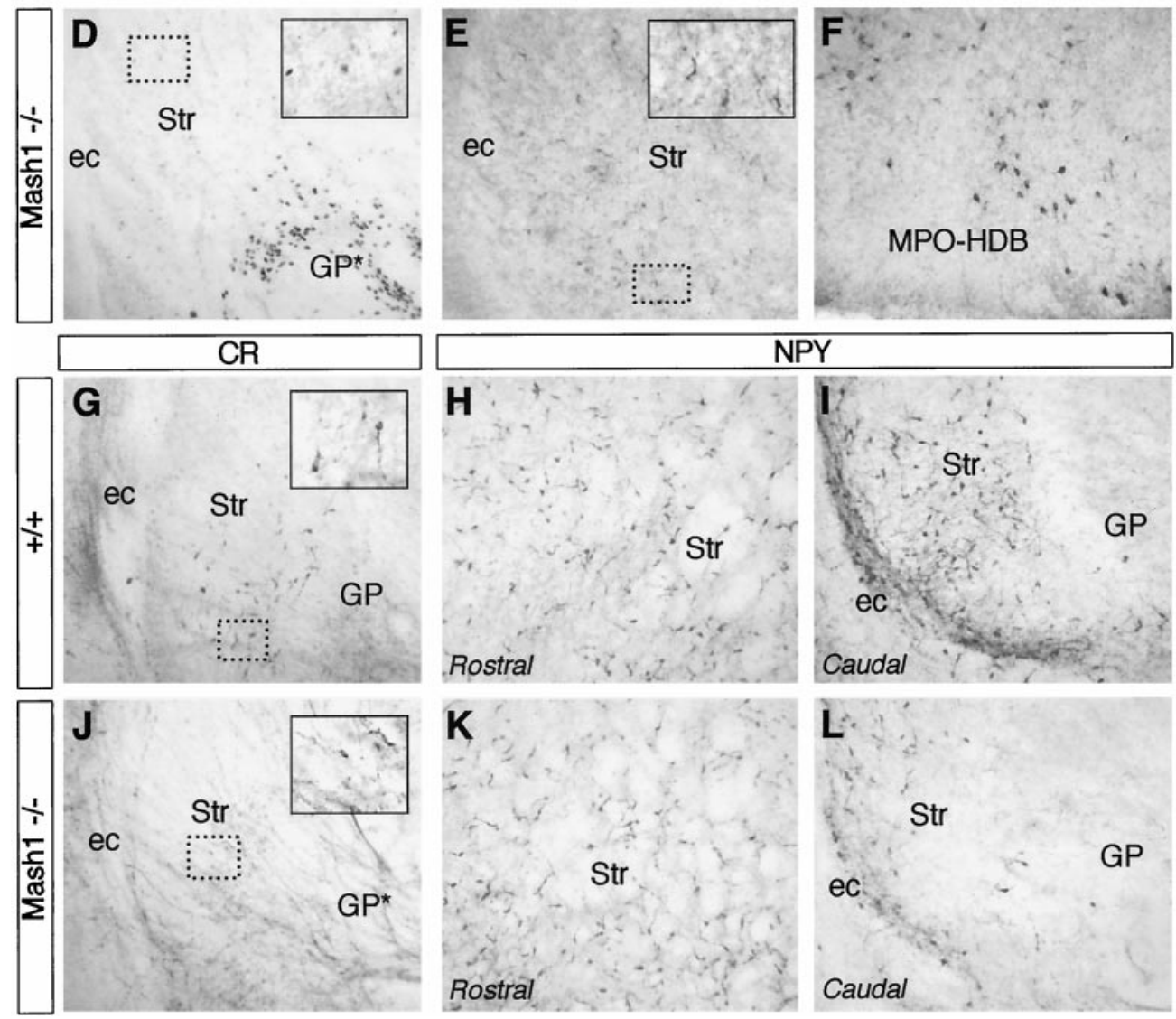

pallidum, substantia innominata, and the bed nucleus of the stria terminalis (Fig. 7A). The striatum also contains scattered $\mathrm{NKX} 2.1^{+}$cells at all rostrocaudal levels at this age (Fig. $7 A$ ). At $\mathrm{P} 0$ only a small number of NKX2.1 ${ }^{+}$cells are located in the proliferative region of the ventral telencephalon (Fig. $7 A$ ), except for the ventral aspect of the lateral ventricle at rostral telencephalic levels, which continues to contain NKX2.1 in the postnatal telencephalon (see Fig. $1 G$ ). In contrast, $D l x 1 / 2$ mutants have a massive accumulation of $\mathrm{NKX} 2.1^{+}$cells in the periventricular region of the mutant MGE (MGE*). In this area NKX2.1 expression is found both in the proliferative zone (SVZ*) and in large ectopic accumulations of nonproliferating densely packed cells (Fig. 7D). Moreover, $\mathrm{NKX} 2.1^{+}$cells spread dorsally through the LGE SVZ, expanding as far as the pallial-subpallial boundary (data not shown).

An analysis of the migration properties of MGE-derived cells was assessed by means of BrdU birthdating. Thus, pregnant animals received a single injection of BrdU at E10.5, E11.5, E12.5, E13.5, and E15.5, and the location of the BrdU-labeled cells was analyzed at birth. In the ventral telencephalon of wild-type mice, E10.5 injections primarily labeled cells in regions superficial to the striatum and pallidum (Fig. $7 B$ ); E11.5 and E12.5 injections labeled cells in the pallidum (data not shown), whereas injections between E11.5 and E15.5 labeled cells throughout the striatum (Fig. 7B; data not shown). In the $D l x 1 / 2$ mutants the early injections (E10.5 and E11.5) labeled cells in the striatum, pallidum, and regions superficial to the basal ganglia (Fig. $7 E$; data not shown); in contrast, most of the mutant cells labeled by either the E12.5 or E13.5 BrdU pulses remained within the mutant proliferative zone (Fig. $7 F$; data not shown). Of note, a large number of the cells that accumulate in the mutant periventricular region are $\mathrm{NKX} 2.1^{+}$ (star in Fig. $7 H$; also compare $7 A$ and $D$ ).

These data indicate that, like in the LGE, Dlxl/2 mutants have a time-dependent block in MGE differentiation, resulting in the accumulation of late-born MGE neurons within the proliferative zone as well as in periventricular neuronal ectopias (stars in Fig. $7 D, G, I, J)$. Consistent with this conclusion is our observation that the number of striatal cholinergic interneurons, which are among the earliest-born cells of the striatum (Semba et al., 1988; Phelps et al., 1989), was less reduced in the $D l x 1 / 2$ mutants $(\sim 2.5$-fold reduction; Figs. $5 C, 8 A, C)$ than that of later-born striatal NPY/SOM/ NOS interneurons (Semba et al., 1988) (approximately sixfold reduction; Figs. $5 C, 8 B, D)$. When the reduced surface area of the Dlx1/2 mutant striatum is taken into account, the density of striatal cholinergic interneurons is increased in Dlx1/2 mutants, whereas the density of striatal NPY/SOM/NOS interneurons is reduced (see Fig. 5C).

Analysis at P0 shows that most of the cells that accumulated in the MGE SVZ* in the Dlx1/2 mutants express NPY, SOM, NOS, 

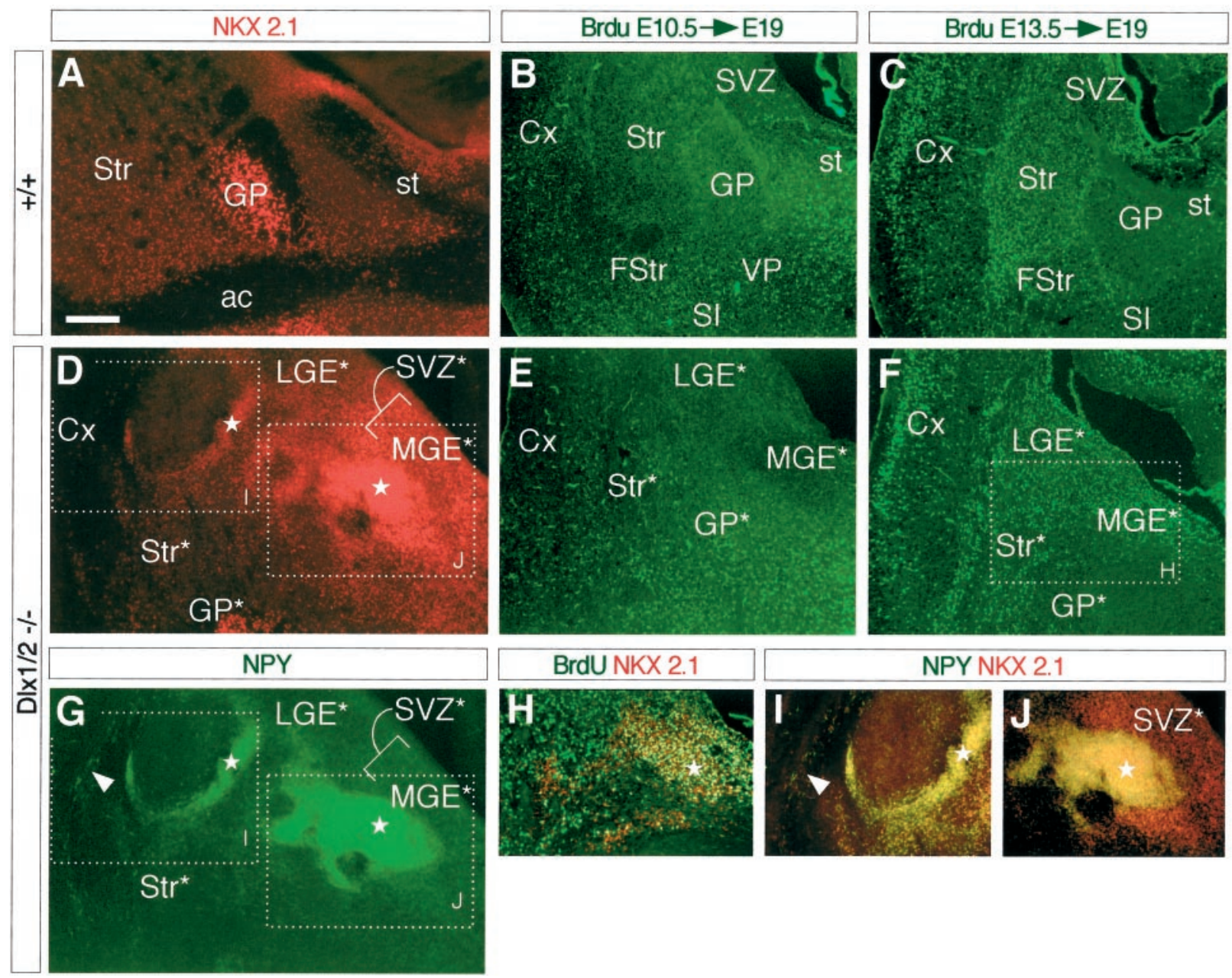

Figure 7. NPY colocalizes with NKX2.1 in the MGE proliferative zone of $D l x 1 / 2$ double mutants. $A, D$, $G$, Coronal sections through the caudal striatum of P0 pups showing NKX2.1 $(A, D)$ and NPY immunoreactivity $(G)$ in wild-type $(A)$ and $D l x 1 / 2$ double mutants $(D$, $G)$. Periventricular neuronal ectopias express both NKX2.1 and NPY in Dlx1/2 double mutants (stars in $D, G, I, J) . I$, $J$, Higher magnification images of neuronal ectopias from the outlined boxed regions. The basal telencephalon of $D l x 1 / 2$ mutants also contains cells that stain only for NPY (arrowhead in $G, I)$ or NKX2.1 $(S V Z *$ in $D, J$ ). $B, C, E$, $F$, Pregnant females received a single injection of BrdU at E10.5 $(B, E)$ or E13.5 $(C, F)$, and the location of labeled cells was analyzed at E19. Note that although the E10.5 injection results in a similar pattern of labeled cells in wild-type and Dlx1/2 mutant embryos, most of the cells labeled by the E13.5 injection in the mutant do not migrate to the mantle but remain within the periventricular region. The cells that accumulate in the mutant $M G E^{*}$ are positive for NKX2.1 ( $H$, higher magnification of the region outlined in the boxed region in $F$ ). ac, Anterior commissure; $C x$, cortex; $e c$, external capsule; $F S t r$, fundus striatum; $G P$, globus pallidus; $G P^{*}$, mutant GP; $L G E$, lateral ganglionic eminence; $L G E^{*}$, mutant LGE; $M G E$, medial ganglionic eminence; $M G E^{*}$, mutant MGE; SI, substantia innominata; Str, striatum; Str*, mutant striatum; $S V Z$, subventricular zone; $S V Z^{*}$, mutant SVZ; VP, ventral pallidum. Scale bar: $A, D, G-J, 150 \mu \mathrm{m} ; B, C, E, F, 200 \mu \mathrm{m}$.

and NKX2.1 (Fig. 7G,I,J; data not shown). In fact, double-labeling experiments demonstrated that NPY and SOM are coexpressed with NKX2.1 in this region (Fig. 7D, G,I,J; data not shown). Therefore, in line with the previous experiments, the analysis of NPY/ $\mathrm{SOM} / \mathrm{NOS}$ striatal neurons in Dlx1/2 mutants suggests that this subtype of striatal interneurons derives primarily from $\mathrm{NKX} 2.1^{+}$ progenitors.

\section{The expression of LIM homeodomain genes Lhx6 and Lhx7 is differentially affected in D/x1/2 double mutants}

Whereas expression of $N k x 2.1$ in the basal telencephalon is required for the formation of most striatal and cortical interneurons (Sussel et al., 1999; present study), nothing is known about the factors that control the differentiation of distinct interneuron subtypes in the telencephalon. In the spinal cord a combinatorial code of homeodomain (LIM, Nkx, Pax) transcription factors controls the identity of different types of ventral neurons (see Tanabe and Jessell, 1996; Briscoe et al., 1999). In the basal ganglia the LIM proteins Lhx6 and Lhx7 are expressed in the developing MGE (Grigoriou et al., 1998; Lavdas et al., 1999; Sussel et al., 1999; O.
Marín and J. L. Rubenstein, unpublished observations) as well as in subsets of neurons in the striatum (Fig. $9 A, B, G, H$ ).

To define the relationship between transcription factor expression and neuronal identity in the striatum, we analyzed the expression of $L h \times 6$ and $L h \times 7$ in the striatum of $N k x 2.1$ mutants at E18.5. In these mutants the cells expressing $L h x 6$ or $L h x 7$ were not found at any rostrocaudal level in the striatum (Fig. 9D,E). Because $N k \times 2.1$ is not expressed in striatal projection neurons (see Fig. $3 A, B)$ and it apparently is not required for their proper differentiation (Fig. 9C,F) (Sussel et al., 1999), these results suggest that Lhx6 and Lhx7 expression most likely is confined to local circuit neurons in the striatum.

Next, we examined $L h x 6$ and $L h x 7$ expression in $D l x 1 / 2$ mutants. At birth, $L h x 6^{+}$cells were found in reduced numbers in the mutant striatum, whereas $L h x 7$ expression was approximately normal or even increased (Fig. 9G,H,J,K). Moreover, both NPY/SOM/NOS and $L h x 6$ were expressed abnormally in the periventricular region (see Figs. $7 G, J, 9 K$ ), suggesting that this transcription factor might be involved in the development of NPY/SOM/NOS interneurons. The expression of $L h x 7$ in $D l x 1 / 2$ mutants suggests, on the other 

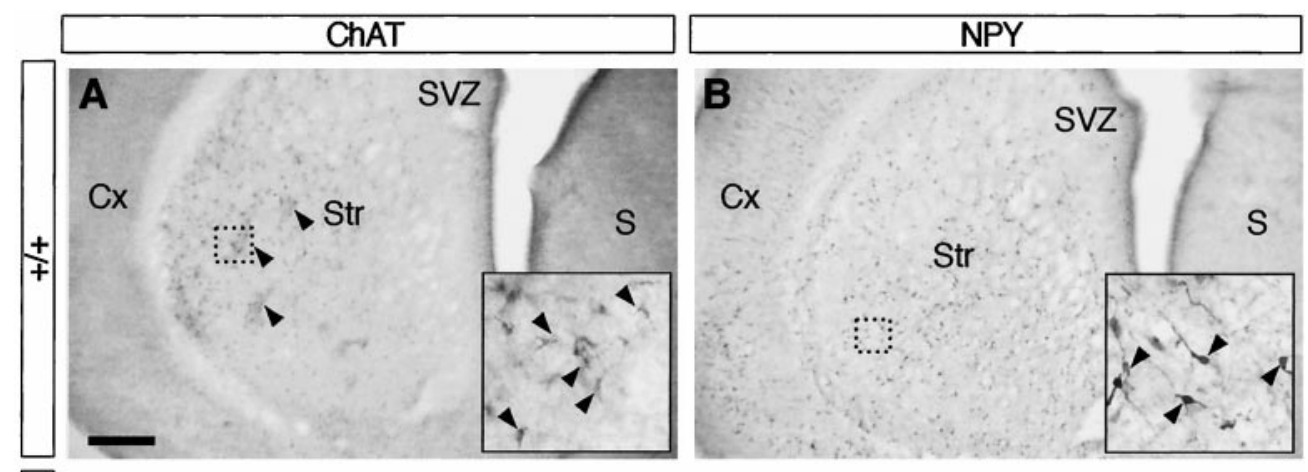

Figure 8. Reduction of striatal interneurons in Dlx1/2 double mutants. $A, B$, Coronal sections showing $\operatorname{ChAT}(A)$ and NPY immunoreactivity $(B)$ in the striatum of $\mathrm{P} 0$ wild-type embryos. $C, D$, Coronal sections showing reduction of ChAT $(C)$ and NPY immunoreactivity $(D)$ in the striatum of $\mathrm{P} 0 \mathrm{Dlx} 1 / 2$ mutant embryos. The dashed line outlines the approximate perimeter of the striatal mantle (based in part on being PCNA-negative; data not shown) in Dlx1/2 mutants. Insets in $A-D$ show higher magnification images of neurons from the outlined boxed regions. Note that $\mathrm{ChAT}^{+}$interneurons are grouped mainly in striatal patches in both wild-type and mutant embryos (arrowheads in $A, C)$. $C x$, Cortex; $S$, septum; Str, striatum; $S t r *$, mutant striatum; $S V Z$, subventricular zone; $S V Z^{*}$, mutant SVZ. Scale bar for $A-D, 250 \mu \mathrm{m}$.
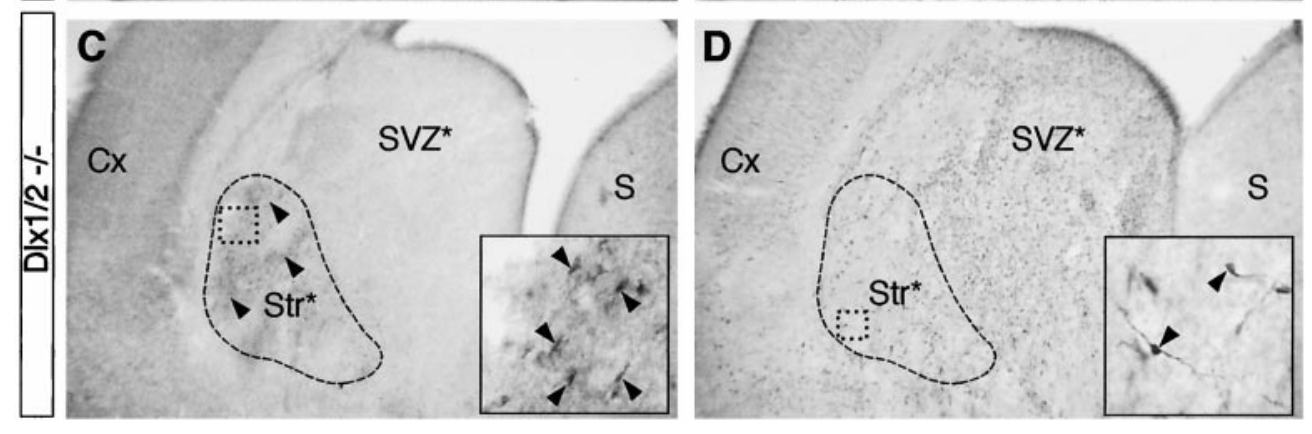

hand, that this transcription factor is involved in the development of a different subset of interneurons (e.g., the $\mathrm{ChAT}^{+}$neurons, which are not present in the periventricular region of $D l \times 1 / 2$ mutants) (see Fig. 7A,C).

\section{DISCUSSION}

In this study we provide evidence that the vast majority of striatal interneurons migrates tangentially from progenitor zones in the MGE and POa/AEP to the postmitotic zone of the LGE. Nkx2.1, which is expressed in progenitor zones of the MGE and POa/AEP and in most mature striatal interneurons, is required for the development of nearly all striatal interneurons. In contrast, Mash1 and Dlx $1 / 2$, which also are expressed in the precursor cells of this region, regulate the development of early- versus late-born interneurons, respectively. Finally, our analysis implicates distinct LIM homeobox genes ( $L h x 6$ and $L h x 7$ ) in the generation of specific subtypes of striatal interneurons.

\section{Most striatal interneurons are derived from NKX2.1 ${ }^{+}$ precursors in the MGE and POa/AEP and tangentially migrate into the striatum}

Recent DiI labeling and transplantation experiments have revealed a robust tangential migration from the MGE to the LGE (Lavdas et al., 1999; Sussel et al., 1999; Wichterle et al., 1999). Here we show, using retroviral cell tracing (see Fig. 2), that cells emanating from the MGE and the adjacent POa/AEP migrate to the developing striatum, where they differentiate into local circuit neurons. Furthermore, this analysis reveals that most striatal cells derived from the MGE/POa/AEP express $N k x 2.1$, whereas none of the LGE-derived cells do.

What subtypes of striatal interneurons derive from the MGE/ $\mathrm{POa} / \mathrm{AEP}$ ? In the adult striatum all cholinergic and $\mathrm{PV}^{+}$and nearly all $\mathrm{CR}^{+}$interneurons coexpress NKX2.1. In contrast, only $\sim 10 \%$ of the NPY/SOM/NOS/NADPHd interneurons contain NKX2.1. These static histochemical analyses suggest that all cholinergic and $\mathrm{PV}^{+}$, most $\mathrm{CR}^{+}$, and some NPY/SOM/NOS/NADPHd striatal interneurons are derived from the MGE/POa/AEP, whereas the LGE is the source of the majority of the NPY/SOM/ NOS/NADPHd and some $\mathrm{CR}^{+}$striatal interneurons. Of note, striatal NPY/SOM/NOS/NADPHd interneurons do not develop in $N k x 2.1$ mutants, raising the possibility that some striatal interneurons might derive from regions other than the MGE (e.g., LGE) but require substances produced from a normal MGE to differentiate and/or survive.

An alternative possibility is, however, that most striatal interneurons actually derive from the MGE/POa/AEP, but some of them (expressing NPY/SOM/NOS/NADPHd) downregulate the expression of $N k x 2.1$ after leaving the proliferative zone. Three independent lines of evidence support this hypothesis: (1) In the absence of $N k \times 2.1$ the striatum does not contain cholinergic or NPY/SOM/NOS/NADPHd interneurons (see Fig. 4); (2) NKX2.1 and NPY/SOM are coexpressed in partially differentiated cells in the proliferative zone of $D l x 1 / 2$ mutants (see Fig. 7; also discussed below); and (3) paleo-, neo-, and archicortical interneurons derived from the MGE do not express $N k x 2.1$, suggesting that they downregulate its expression after leaving the proliferative zone (Sussel et al., 1999; S. Anderson, O. Marín, and J. L. Rubenstein, unpublished observations). In summary, we suggest that nearly all striatal interneurons are derived from the MGE/POa/AEP region. The only exception may be a few $\mathrm{CR}^{+}$interneurons for which the origin is not known.

Our data differ from some of the conclusions of an earlier study that used transplantation experiments to investigate the origins of rat cholinergic and $\mathrm{SOM}^{+}$striatal interneurons (Olsson et al., 1998). In agreement with our results, striatal cholinergic interneurons were found mainly in grafts derived from the early MGE (E12.5 in the rat; Olsson et al., 1998). In contrast, Olsson and colleagues (1998) suggest that striatal $\mathrm{SOM}^{+}$interneurons are generated from both the LGE and MGE. However, because $\mathrm{SOM}^{+}$ striatal interneurons are born as early as E12 in the rat (Semba et al., 1988), it is possible that in the experiments described by Olsson et al. (1998) the transplanted LGE already had MGE-derived cells within it.

\section{DIx1, DIx2, and Mash1 regulate the generation of early- and late-born striatal interneurons}

Dlx1, Dlx2, and Mash1 are expressed in progenitor cells of the LGE and MGE (Porteus et al., 1994; Liu et al., 1997; Eisenstat et al., 1999; Torii et al., 1999). Dlx1/2 double mutants previously were shown to have a time-dependent block in the differentiation of radially migrating striatal projection neurons and tangentially migrating cortical local circuit neurons (Anderson et al., 1997a,b). Mash1 mutants have a complementary defect that affects the generation of early-born neurons in the ventral telencephalon (Casa- 

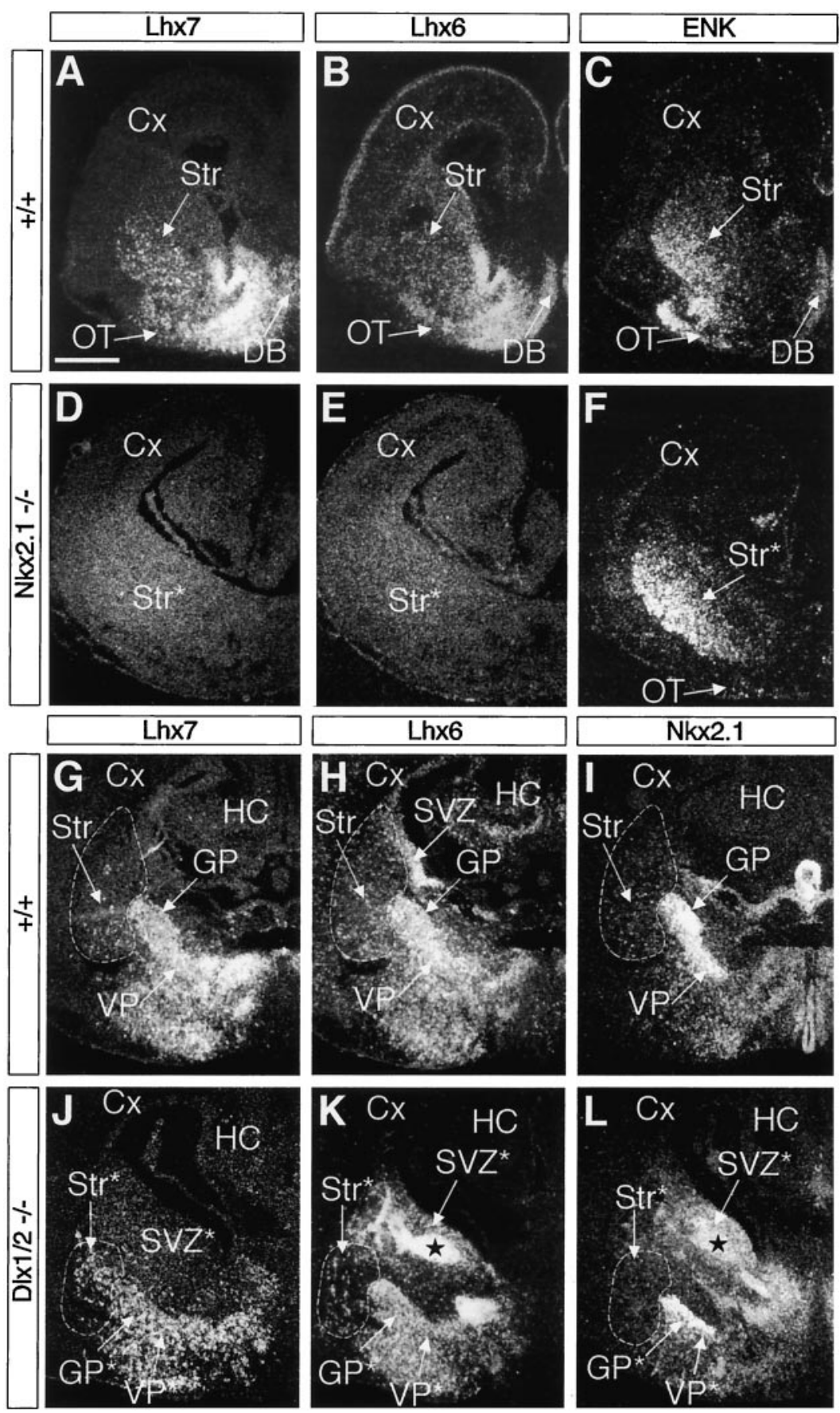

Figure 9. Expression of the LIM homeodomain genes Lhx6 and $L h x 7$ in the striatum of $N k x 2.1$ mutants and Dlx1/2 double mutants. $A-C, G-I$, Serial coronal sections through the telencephalon of an E18.5 wild-type fetus showing $\operatorname{Lh} x 7(A), \operatorname{Lh} x 6$ $(B)$, and $E N K(C)$ expression in the striatum, and of a P0 pup showing $\operatorname{Lhx} 7(G)$, $\operatorname{lh} x 6(H)$, and $N k x 2.1(I)$ expression in the basal telencephalon. $D-F$, Serial coronal sections from an E18.5 Nkx2.1 mutant showing loss of $L h x 7(D)$ and $L h x 6(E)$ expression and normal $E N K(F)$ expression in the expanded striatum. $J-L$, Serial coronal sections from a P0 Dlx1/2 mutant showing normal $L h x 7(J)$ expression and reduced $L h x 6(K)$ and $N k \times 2.1(L)$ expression in the striatum. $G-L$, The dashed line outlines the approximate perimeter of the striatal mantle. Note that Lhx6 expression accumulates in periventricular neuronal ectopias that also express $N k \times 2.1$ (stars in $K, L)$, but not $L h x 7(J) . J-L$, The dashed line approximates the extension of the striatal mantle in $D l x 1 / 2$ mutants. $C x$, Cortex; $D B$, diagonal band; $H C$, hippocampus; $O T$, olfactory tubercle; $G P$, globus pallidus; $G P^{*}$, mutant GP; Str, striatum; $S t r^{*}$, mutant striatum; $S V Z$, subventricular zone; $S V Z *$, mutant SVZ; $V P$, ventral pallidum; $V P^{*}$, mutant VP. Scale bar for $A-L, 500 \mu \mathrm{m}$. rosa et al., 1999). Here we show that these mutants have similar time-dependent defects in the generation of the MGE-derived striatal interneurons (see Figs. 5-8). In addition, the $D l \times 1 / 2$ mutants accumulate periventricular ectopia of partially differentiated neurons deep to the subventricular zone (see Fig. 7). As noted above, these ectopia contain cells that are $\mathrm{NKX}_{2} .1^{+} / \mathrm{NPY}^{+}$, implying that $D l x 1 / 2$ are required (directly or indirectly) to enable these striatal interneurons to repress $N k x 2.1$ expression. We suggest that Mash1 and Dlx1/2 regulate the balance between early versus late differentiation in the basal telencephalon (K. Yun and J. L. Rubenstein, unpublished observations), whereas Nkx2.1 regulates regional and cell-type specification in this region (Fig. 10).

\section{Specification of neuronal identity in the MGE/POa/AEP}

Fate maps of the early telencephalon support the hypothesis that derivatives of the MGE/POa/AEP include the dorsal pallidum, ventral pallidum, and basal magnocellular complex (Rubenstein et al., 1998; I. Cobos, K. Shimamura, J. L. Rubenstein, L. Puelles, and S. Martínez, unpublished observations). In the present study we have shown that this $\mathrm{NKX} 2.1^{+}$region gives rise to neurons that express either acetylcholine or GABA. It is unknown what controls the switch between these two phenotypes. In addition, each of these two cell types gives rise to cells that are either radially migrating projection neurons or local circuit neurons that migrate tangentially to the striatum and cerebral cortex (Fig. 10D) (Anderson et al., 1997b; Lavdas et al., 1999; Sussel et al., 1999; present study).

Thus, the basal telencephalon contains two main types of cholinergic neurons, the local circuit neurons of the striatum and the projection neurons of the basal forebrain system, including the nucleus basalis magnocellularis, diagonal band, and medial septum (Mesulam et al., 1983a,b; 1984). Although the cholinergic neurons of the striatum and basal forebrain system are located within different nuclei and are known to have very different functions, 

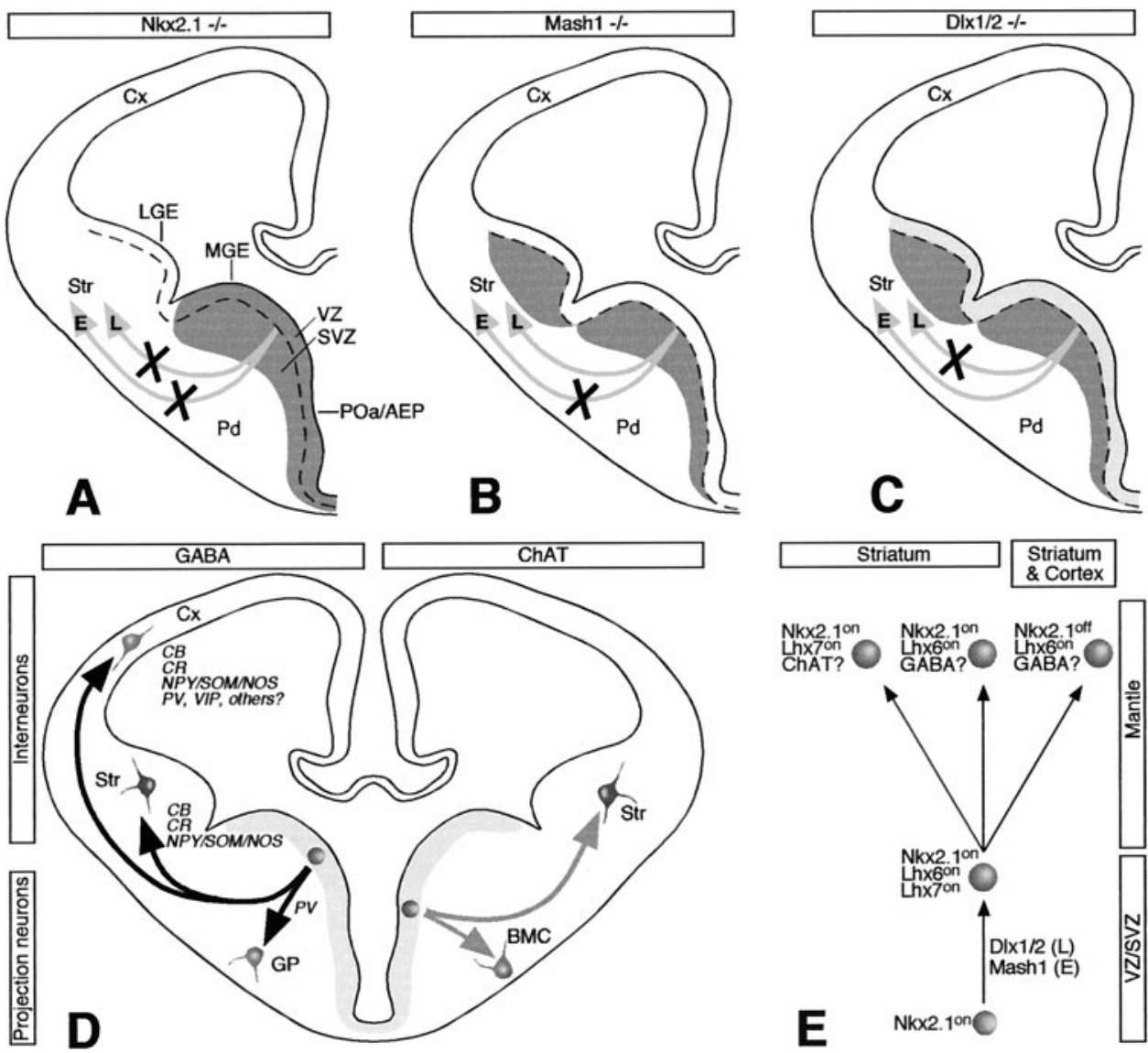

Figure 10. Schemas illustrating the origin and migration of neurons derived from the NKX2.1 ${ }^{+}$proliferative region in the basal telencephalon and the genes that are involved in their specification and differentiation. $A-C$, These drawings are based on a coronal section of a mouse E12.5 right telencephalic hemisphere. The light gray arrow-tipped lines indicate early $(E)$ and late $(L)$ tangential migrations that originate in the $\mathrm{NKX} 2.1^{+}$progenitor zone $($dark gray) of the MGE and POA/AEP. A dashed line indicates the limit between the VZ and SVZ. A, Both tangential migrations are lost (indicated by black $X s$ ) in the $N k \times 2.1$ mutant mouse because of a ventral-to-dorsal respecification of the progenitor zone (Sussel et al.; 1999). B, The Mash1 mutation preferentially blocks the early $(E)$ tangential migration. MASH1 expression is in a subset of VZ cells (light gray) and in most SVZ cells (dark gray). $C$, The Dlx1/2 mutation preferentially blocks the late $(L)$ tangential migration. DLX1 and DLX2 expression is in a subset of VZ cells (light gray) and in most SVZ cells (dark gray). D, Schema of a coronal section through an E12.5 mouse telencephalon. The NKX2.1 ${ }^{+} \mathrm{VZ}$ is indicated in light gray. Migrations of GABAergic cells from the NKX2.1 $1^{+}$progenitor zone are indicated on the left. A radial migration produces the GABAergic projection neurons of the globus pallidus $(G P)$, whereas tangential migrations produce GABAergic interneurons of the striatum (this study) and cerebral cortex (Anderson et al., 1999; Sussel et al., 1999; Anderson, Marín, and Rubenstein, unpublished observations). Although the origin of some cortical interneuron subtypes, such as those containing PV or VIP, has not been demonstrated, we hypothesize that they also may derive from the basal telencephalon. Migrations of cholinergic $(C h A T)$ cells from the NKX2.1 ${ }^{+}$progenitor zone are indicated on the right. A radial migration produces the cholinergic projection neurons of the basal magnocellular complex $(B M C)$, whereas tangential migrations produce cholinergic interneurons of the striatum (this study). E, Model describing some of the genes that regulate the production of tangentially migrating cells from NKX2.1 ${ }^{+}$progenitor cells. Dlx1/2 and Mash1 regulate the production of secondary progenitor cells that express $L h x 6$ and $L h x 7$ (we do not know whether a single cell expresses both $L h x$ genes). From these cells we hypothesize that three types of interneurons are formed, two of which migrate to the striatum and a third that contributes interneurons to both the striatum and cortex. $C B$, Calbindin; $C R$, calretinin; $C x$, cortex; $N O S$, nitric oxide synthase; $N P Y$, neuropeptide Y; $P d$, pallidum; $P V$, parvalbumin; $S O M$, somatostatin; Str, striatum; SVZ, subventricular zone; VIP, vasointestinal peptide; VZ, ventricular zone.

they are generated at approximately the same time (Semba et al., 1988; Brady et al., 1989; Phelps et al., 1989). Moreover, the present data demonstrate that cholinergic neurons in the ventral telencephalon derive from a common germinal source, the MGE/POa/AEP region, and that their development requires $N k \times 2.1$ function.

As in the case of the cholinergic neurons, the neurotransmitter GABA is expressed both in local circuit and projection neuronal populations of the basal telencephalon that may share a common origin. For example, GABA is expressed in subsets of striatal interneurons and globus pallidus projection neurons (Kita and Kitai, 1994; Kawaguchi et al., 1995; Parent and Hazrati, 1995); in both cases their development appears to be dependent on $N k \times 2.1$ function (Sussel et al., 1999; present study; Marín and Rubenstein, unpublished observations).

It has been proposed that neurons sharing the same chemical phenotype (e.g., cholinergic neurons) from different areas of the telencephalon are neurogenetically homologous and that their final morphology and connectivity depend primarily on extrinsic factors (Gähwiler and Hefti, 1985; Semba et al., 1988; Campbell et al.,
1995; Sadikot and Sasseville, 1997). An alternative model is that intrinsic factors distinguish projection and interneurons, even when they share the same neurotransmitter phenotype. This would be necessary to explain their distinct migratory pathways. For instance, basal forebrain cholinergic and pallidal GABAergic projection neurons are superficial to the progenitor zones from which they derive and thus seem to follow a radial migration, whereas cholinergic and GABAergic interneurons migrate tangentially to the striatum.

What are the genes that regulate the choice between becoming a radially migrating projection neuron or a tangentially migrating local circuit neuron? The answer to this question is not known, but clues may be provided by studies of dorsoventral patterning of the spinal cord and hindbrain. In these structures $N k x$ genes $(N k x 2.2$ and $N k \times 6.1$ ) specify the identity of the progenitor cells of distinct longitudinal domains in the ventral neural tube (Qiu et al., 1998; Briscoe et al., 1999; M. Sander, S. Paydar, J. Ericson, J. Briscoe, E. Berber, M. German, T. Jessell, and J. Rubenstein, unpublished observations). Nkx6.1 is upstream of several homeodomain tran- 
scription factors that are required for the development of projection neurons (cholinergic motor neurons) and interneurons (V2 cells) (Sander, Paydar, Ericson, Briscoe, Berber, German, Jessell, and Rubenstein, unpublished observations). Among the downstream genes are Isll and Lhx3, which encode LIM-homeodomain proteins that have essential roles in motor neuron development (Pfaff et al., 1996; Sharma et al., 1998). The combinatorial expression of LIM-homeodomain proteins defines specific populations of neurons in the ventral CNS (Tsuchida et al., 1994; Appel et al., 1995; Tanabe and Jessell, 1996).

These results drew our attention to the Lhx6 and $\operatorname{Lh} x 7$ LIMhomeobox genes, which are expressed in the MGE and are dependent on Nkx2.1 function (Sussel et al., 1999). Thus, these genes are candidates for defining cell type specification within the basal telencephalon. However, they are expressed both in pallidal projection neurons and tangentially migrating interneurons (see Fig. 9 ), implying that other factors are required to define projection neurons from interneurons. At this point the intrinsic factors that determine whether a cell migrates radially or tangentially are not known. On the other hand, there is evidence that the secreted molecule SLIT1 regulates the radial migration of GABAergic neurons derived from the LGE (Zhu et al., 1999).

Although $\operatorname{Lh} x 6$ and $\operatorname{Lh} x 7$ may not regulate the choice between projection and interneurons, they may have a role in regulating the development of distinct subsets of striatal interneurons (Fig. 10E). We base this hypothesis on our observations of their expression in the $D l x 1 / 2$ mutants. In these animals the patterns of $L h x 6$ and NPY/SOM/NOS expression are correlated (see Figs. 7G,I,J, 9K), whereas the expression of $L h \times 7$ correlates with the distribution of $\mathrm{ChAT}^{+}$neurons (see Figs. $8 C, 9 J$ ).

\section{Telencephalic GABAergic and cholinergic interneurons are derived from the basal ganglia}

The results of this and other studies strongly suggest that the basal ganglia primordia are the origin of the majority of interneurons present in the mature striatum, cortex, and olfactory bulb (de Carlos et al., 1996; Anderson et al., 1997b, 1999; Tamamaki et al., 1997; Casarosa et al., 1999; Lavdas et al., 1999; Sussel et al., 1999; Wichterle et al., 1999; Anderson, Marín, and Rubenstein, unpublished observations). Several lines of evidence suggest that the MGE is a major source of tangentially migrating interneurons to both the striatum and cortex (Anderson et al., 1999; Lavdas et al., 1999; Sussel et al., 1999; Wichterle et al., 1999; Anderson, Marín, and Rubenstein, unpublished observations). Interestingly, the LGE appears to be the source of a different pool of cortical and olfactory bulb interneurons, as demonstrated by the comparative analysis of Dlx1/2 and Nkx2.1 mutants (Anderson et al., 1997a,b, 1999; Sussel et al., 1999; Anderson, Marín, and Rubenstein, unpublished observations).

\section{Theoretical issues}

The findings described in this and other studies (de Carlos et al., 1996; Anderson et al., 1997b, 1999; Tamamaki et al., 1997; Casarosa et al., 1999; Lavdas et al., 1999; Sussel et al., 1999; Wichterle et al., 1999; Anderson, Marín, and Rubenstein, unpublished observations) raise several interesting theoretical issues. First, whereas radially migrating cells could translate the positional information values of their precursors to the overlying mantle zone, tangentially migrating cells would not. Thus, tangentially migrating local circuit neurons may not have a role in the initial formation of topographic connectivity maps, whereas radially migrating cells do.

Second, why are striatal, cortical, and olfactory bulb interneurons generated in the basal telencephalon, instead of locally? It may be that cell type specification is tightly coupled to regional specification. Thus, induction of the transcription factors that regulate development of cholinergic neurons (e.g., Nkx2.1) (Sussel et al., 1999; this study) and GABAergic neurons (e.g., Dlx1 and Dlx2) (Anderson et al., 1997a,b, 1999; Bulfone et al., 1998) may take place only in proximity to morphogens that are implicated in specification of the basal telencephalon (e.g., SHH) (Ericson et al.,
1995; Chiang et al., 1996; Shimamura and Rubenstein, 1997; Kohtz et al., 1998). This would imply that the LGE is incapable of producing cholinergic cells and that the cortex is incapable of producing GABAergic cells, thus requiring that these cell types tangentially migrate from proliferative zones where they can be produced.

\section{REFERENCES}

Anderson KD, Reiner A (1991) Immunohistochemical localization of DARPP-32 in striatal projection neurons and striatal interneurons: implications for the localization of D1-like dopamine receptors on different types of striatal neurons. Brain Res 568:235-243.

Anderson SA, Qiu M, Bulfone A, Eisenstat DD, Meneses J, Pedersen R, Rubenstein JL (1997a) Mutations of the homeobox genes Dlx-1 and $D l x-2$ disrupt the striatal subventricular zone and differentiation of late born striatal neurons. Neuron 19:27-37.

Anderson SA, Eisenstat DD, Shi L, Rubenstein JL (1997b) Interneuron migration from basal forebrain to neocortex: dependence on $D l x$ genes. Science 278:474-476.

Anderson SA, Mione M, Yun K, Rubenstein JLR (1999) Differential origins of neocortical projection and local circuit neurons; role of $D l x$ genes in neocortical interneuronogenesis. Cereb Cortex 9:646-654.

Appel B, Korzh V, Glasgow E, Thor S, Edlund T, Dawid IB, Eisen JS (1995) Motoneuron fate specification revealed by patterned LIM homeobox gene expression in embryonic zebrafish. Development 121:4117-4125.

Bennett BD, Bolam JP (1993) Two populations of calbindin D28k-immunoreactive neurones in the striatum of the rat. Brain Res 610:305-310.

Brady DR, Phelps PE, Vaughn JE (1989) Neurogenesis of basal forebrain cholinergic neurons in rat. Dev Brain Res 47:81-92.

Briscoe J, Sussel L, Serup P, Hartigan-O'Connor D, Jessell TM, Rubenstein JL, Ericson J (1999) Homeobox gene Nkx2.2 and specification of neuronal identity by graded Sonic hedgehog signaling. Nature 398:622-627.

Bulfone A, Puelles L, Porteus MH, Frohman MA, Martin GR, Rubenstein JL (1993) Spatially restricted expression of $D l x-1, D l x-2$ (Tes-1), Gbx-2, and Wnt-3 in the embryonic day 12.5 mouse forebrain defines potential transverse and longitudinal segmental boundaries. J Neurosci 13:3155-3172.

Bulfone A, Wang F, Hevner R, Anderson S, Cutforth T, Chen S, Meneses J, Pedersen R, Axel R, Rubenstein JL (1998) An olfactory sensory map develops in the absence of normal projection neurons or GABAergic interneurons. Neuron 21:1273-1282.

Campbell K, Olsson M, Björklund A (1995) Regional incorporation and site-specific differentiation of striatal precursors transplanted to the embryonic forebrain ventricle. Neuron 15:1259-1273.

Casarosa S, Fode C, Guillemot F (1999) Mash1 regulates neurogenesis in the ventral telencephalon. Development 126:525-534.

Cau E, Gradwohl G, Fode C, Guillemot F (1997) Mash1 activates a cascade of bHLH regulators in olfactory neuron progenitors. Development 124:1611-1621.

Chiang C, Litingtung Y, Lee E, Young KE, Corden JL, Westphal H, Beachy PA (1996) Cyclopia and defective axial patterning in mice lacking Sonic hedgehog gene function. Nature 383:407-413.

Deacon TW, Pakzaban P, Isacson O (1994) The lateral ganglionic eminence is the origin of cells committed to striatal phenotypes: neural transplantation and developmental evidence. Brain Res 668:211-219.

de Carlos JA, López-Mascaraque L, Valverde F (1996) Dynamics of cell migration from the lateral ganglionic eminence in the rat. J Neurosci 16:6146-6156.

Eisenstat DD, Liu JK, Mione M, Zhong W, Yu G, Anderson S, Ghattas I, Puelles L, Rubenstein JLR (1999) DLX-1, DLX-2, and DLX-5 expression define distinct stages of basal forebrain differentiation. J Comp Neurol 414:217-237.

Ericson J, Muhr J, Placzek M, Lints T, Jessell TM, Edlund T (1995) Sonic hedgehog induces the differentiation of ventral forebrain neurons: a common signal for ventral patterning within the neural tube. Cell $81: 747-756$.

Figueredo-Cardenas G, Morello M, Sancesario G, Bernardi G, Reiner A (1996) Colocalization of somatostatin, neuropeptide Y, neuronal nitric oxide synthase, and NADPH-diaphorase in striatal interneurons in rats. Brain Res 735:317-324.

Gähwiler BH, Hefti F (1985) Striatal acetylcholinesterase-containing interneurons innervate hippocampal tissue in cocultured slices. Brain Res 350:311-314.

Gerfen CR (1992) The neostriatal mosaic: multiple levels of compartmental organization. Trends Neurosci 15:133-139.

Gerfen CR, Wilson CJ (1996) The basal ganglia. In: Handbook of chemical neuroanatomy, Vol 12, Integrated systems in the CNS, Pt III (Swanson L, Björklund A, Hökfelt T, eds), pp 371-468. Amsterdam: Elsevier. Grigoriou M, Tucker AS, Sharpe PT, Pachnis V (1998) Expression and regulation of $\operatorname{Lh} x 6$ and $\operatorname{Lh} x 7$, a novel subfamily of LIM homeodomain encoding genes, suggests a role in mammalian head development. Development 125:2063-2074.

Guillemot F, Joyner AL (1993) Dynamic expression of the murine achaete-scute homologue Mash-1 in the developing nervous system. Mech Dev 42:171-185. 
Guillemot F, Lo LC, Johnson JE, Auerbach A, Anderson DJ, Joyner AL (1993) Mammalian achaete-scute homolog 1 is required for the early development of olfactory and autonomic neurons. Cell 75:463-476.

Heimer L (1995) The basal ganglia. In: The rat nervous system (Paxinos G, ed). San Diego: Academic.

Hirsch MR, Tiveron MC, Guillemot F, Brunet JF, Goridis C (1998) Control of noradrenergic differentiation and Phox $2 a$ expression by MASH1 in the central and peripheral nervous system. Development 125:599-608.

Horton S, Meredith A, Richardson JA, Johnson JE (1999) Correct coordination of neuronal differentiation events in ventral forebrain requires the bHLH factor MASH1. Mol Cell Neurosci 14:355-369.

Hsieh-Li HM, Witte DP, Szucsik JC, Weinstein M, Li H, Potter SS (1995) $G s h-2$, a murine homeobox gene expressed in the developing brain. Mech Dev 50:177-186.

Kawaguchi Y (1997) Neostriatal cell subtypes and their functional roles. Neurosci Res 27:1-8.

Kawaguchi Y, Wilson CJ, Augood SJ, Emson PC (1995) Striatal interneurones: chemical, physiological, and morphological characterization. Trends Neurosci [Erratum (1996) 19:143] 18:527-535.

Kita H, Kitai ST (1994) The morphology of globus pallidus projection neurons in the rat: an intracellular staining study. Brain Res 636:308-319.

Kiyama H, Seto-Ohshima A, Emson PC (1990) Calbindin D28k as a marker for the degeneration of the striatonigral pathway in Huntington's disease. Brain Res 525:209-214.

Kohtz JD, Baker DP, Corte G, Fishell G (1998) Regionalization within the mammalian telencephalon is mediated by changes in responsiveness to Sonic hedgehog. Development 125:5079-5089.

Kubota Y, Kawaguchi Y (1993) Spatial distributions of chemically identified intrinsic neurons in relation to patch and matrix compartments of rat neostriatum. J Comp Neurol 332:499-513.

Lavdas AA, Grigoriou M, Pachnis V, Parnavelas JG (1999) The medial ganglionic eminence gives rise to a population of early neurons in the developing cerebral cortex. J Neurosci 19:7881-7888.

Liu FC, Graybiel AM (1992) Transient calbindin-D28k-positive systems in the telencephalon: ganglionic eminence, developing striatum, and cerebral cortex. J Neurosci 12:674-690.

Liu JK, Ghattas I, Liu S, Chen S, Rubenstein JL (1997) Dlx genes encode DNA-binding proteins that are expressed in an overlapping and sequential pattern during basal ganglia differentiation. Dev Dyn 210:498-512.

Lo LC, Johnson JE, Wuenschell CW, Saito T, Anderson DJ (1991) Mammalian achaete-scute homolog 1 is transiently expressed by spatially restricted subsets of early neuroepithelial and neural crest cells. Genes Dev 5:1524-1537.

Marín O, Smeets WJ, González A (1998) Basal ganglia organization in amphibians: evidence for a common pattern in tetrapods. Prog Neurobiol 55:363-397.

Mesulam MM, Mufson EJ, Levey AI, Wainer BH (1983a) Cholinergic innervation of cortex by the basal forebrain: cytochemistry and cortical connections of the septal area, diagonal band nuclei, nucleus basalis (substantia innominata), and hypothalamus in the rhesus monkey. J Comp Neurol 214:170-197.

Mesulam MM, Mufson EJ, Wainer BH, Levey AI (1983b) Central cholinergic pathways in the rat: an overview based on an alternative nomenclature (Ch1-Ch6). Neuroscience 10:1185-1201.

Olsson M, Campbell K, Wictorin K, Björklund A (1995) Projection neurons in fetal striatal transplants are predominantly derived from the lateral ganglionic eminence. Neuroscience 69:1169-1182.

Olsson M, Björklund A, Campbell K (1998) Early specification of striatal projection neurons and interneuronal subtypes in the lateral and medial ganglionic eminence. Neuroscience 84:867-876.

Ory DS, Neugeboren BA, Mulligan RC (1996) A stable human-derived packaging cell line for production of high titer retrovirus/vesicular stomatitis virus G pseudotypes. Proc Natl Acad Sci USA 93:11400-11406.

Parent A, Hazrati LN (1995) Functional anatomy of the basal ganglia. I. The corticobasal ganglia-thalamo-cortical loop. Brain Res Rev 20:91-127.

Pfaff SL, Mendelsohn M, Stewart CL, Edlund T, Jessell TM (1996) Requirement for LIM homeobox gene Isl1 in motor neuron generation reveals a motor neuron-dependent step in interneuron differentiation. Cell 84:309-320.

Phelps PE, Brady DR, Vaughn JE (1989) The generation and differenti- ation of cholinergic neurons in rat caudate-putamen. Dev Brain Res 46:47-60.

Porteus MH, Bulfone A, Liu JK, Puelles L, Lo LC, Rubenstein JL (1994) DLX-2, MASH-1, and MAP-2 expression and bromodeoxyuridine incorporation define molecularly distinct cell populations in the embryonic mouse forebrain. J Neurosci 14:6370-6383.

Price M, Lazzaro D, Pohl T, Mattei MG, Rüther U, Olivo JC, Duboule D, Di Lauro R (1992) Regional expression of the homeobox gene $N k x-2.2$ in the developing mammalian forebrain. Neuron 8:241-255.

Puelles L, Kuwana E, Puelles E, Rubenstein JL (1999) Comparison of the mammalian and avian telencephalon from the perspective of gene expression data. Eur J Morphol 37:139-150.

Qiu M, Bulfone A, Ghattas I, Meneses JJ, Christensen L, Sharpe PT, Presley R, Pedersen RA, Rubenstein JL (1997) Role of the Dlx homeobox genes in proximodistal patterning of the branchial arches: mutations of $D l x-1, D l x-2$, and $D l x-1$ and -2 alter morphogenesis of proximal skeletal and soft tissue structures derived from the first and second arches. Dev Biol 185:165-184.

Qiu M, Shimamura K, Sussel L, Chen S, Rubenstein JL (1998) Control of anteroposterior and dorsoventral domains of Nkx-6.1 gene expression relative to other Nkx genes during vertebrate CNS development. Mech Dev 72:77-88.

Rubenstein JL, Shimamura K, Martinez S, Puelles L (1998) Regionalization of the prosencephalic neural plate. Annu Rev Neurosci 21:445-477.

Sadikot AF, Sasseville R (1997) Neurogenesis in the mammalian neostriatum and nucleus accumbens: parvalbumin-immunoreactive GABAergic interneurons. J Comp Neurol 389:193-211.

Schlösser B, Klausa G, Prime G, Ten Bruggencate G (1999) Postnatal development of calretinin- and parvalbumin-positive interneurons in the rat neostriatum: an immunohistochemical study. J Comp Neurol 405:185-198.

Semba K, Vincent SR, Fibiger HC (1988) Different times of origin of choline acetyltransferase- and somatostatin-immunoreactive neurons in the rat striatum. J Neurosci 8:3937-3944.

Sharma K, Sheng HZ, Lettieri K, Li H, Karavanov A, Potter S, Westphal H, Pfaff SL (1998) LIM homeodomain factors Lhx3 and Lhx4 assign subtype identities for motor neurons. Cell 95:817-828.

Shimaura K, Rubenstein JL (1997) Inductive interactions direct early regionalization of the mouse forebrain. Development 124:2709-2718.

Shimamura K, Hartigan DJ, Martinez S, Puelles L, Rubenstein JL (1995) Longitudinal organization of the anterior neural plate and neural tube. Development 121:3923-3933.

Sommer L, Shah N, Rao M, Anderson DJ (1995) The cellular function of MASH1 in autonomic neurogenesis. Neuron 15:1245-1258.

Sussel L, Marín O, Kimura S, Rubenstein JL (1999) Loss of Nkx2.1 homeobox gene function results in a ventral to dorsal molecular respecification within the basal telencephalon: evidence for a transformation of the pallidum into the striatum. Development 126:3359-3370.

Szucsik JC, Witte DP, Li H, Pixley SK, Small KM, Potter SS (1997) Altered forebrain and hindbrain development in mice mutant for the Gsh-2 homeobox gene. Dev Biol 191:230-242.

Tamamaki N, Fujimori KE, Takauji R (1997) Origin and route of tangentially migrating neurons in the developing neocortical intermediate zone. J Neurosci 17:8313-8323.

Tanabe Y, Jessell TM (1996) Diversity and pattern in the developing spinal cord. Science 274:1115-1123.

Toresson H, Mata de Urquiza A, Fagerström C, Perlmann T, Campbell K (1999) Retinoids are produced by glia in the lateral ganglionic eminence and regulate striatal neuron differentiation. Development 126:1317-1326.

Torii M, Matsuzaki F, Osumi N, Kaibuchi K, Nakamura S, Casarosa S, Guillemot F, Nakafuku M (1999) Transcription factors Mash-1 and Prox-1 delineate early steps in differentiation of neural stem cells in the developing central nervous system. Development 126:443-456.

Tsuchida T, Ensini M, Morton SB, Baldassare M, Edlund T, Jessell TM, Pfaff SL (1994) Topographic organization of embryonic motor neurons defined by expression of LIM homeobox genes. Cell 79:957-970.

Wichterle H, Garcia-Verdugo JM, Herrera DG, Alvarez-Buylla A (1999) Young neurons from medial ganglionic eminence disperse in adult and embryonic brain. Nat Neurosci 2:461-466.

Zhu Y, Li H, Zhou L, Wu JY, Rao Y (1999) Cellular and molecular guidance of GABAergic neuronal migration from an extracortical origin to the neocortex. Neuron 23:473-485. 